\title{
Auctions with signaling concerns
}

\section{Olivier Bos ${ }^{1,2,3}$ (1) | Tom Truyts ${ }^{4,5}$}

\author{
${ }^{1}$ LEMMA, Panthéon-Assas University, Paris, France \\ ${ }^{2}$ Institut Universitaire de France (IUF), Paris, France \\ ${ }^{3}$ ZEW - Leibniz Centre for European Economic Research, Mannheim, Germany \\ ${ }^{4}$ CEREC, Saint-Louis University-Brussels, Brussels, Belgium \\ ${ }^{5}$ Center for Economic Studies, University of Leuven, Leuven, Belgium
}

\section{Correspondence}

Olivier Bos, LEMMA, Panthéon-Assas

University, 4 rue Blaise Desgoffe, 75006

Paris, France.

Email: olivier.bos@u-paris2.fr

\section{Funding information}

ANR, Grant/Award Number: ANR-12-

JSH1-0009; ARC, Grant/Award Number: $\mathrm{n}^{\circ} 15 / 20-072$

\begin{abstract}
We study a symmetric private value auction with signaling, in which the auction outcome is used by an outside observer to infer the bidders' types. We elicit conditions under which an essentially unique D1 equilibrium bidding function exists in the second-price and the English auctions. We establish there is no equivalence between these two auction designs, neither in bidding strategies nor in expected revenue. This is because the presence or the absence of an increasing price clock affects signaling incentives differently in both auction formats, and thereby also the bidders' incentives to overbid their types. This leads to a strictly higher expected revenue in the second-price auction than in the English auction. Our analysis is completed by a comparison with other disclosure policies. Applications include art auctions and charity auctions.
\end{abstract}

\section{1 | INTRODUCTION}

Signaling constitutes an important motivation and determinant for many forms of publicly observable behavior of individuals and organizations. Humans tend to universally care about what others think about them. This is either because of innate tastes, as humans intrinsically care about others' esteem, or because of instrumental reasons, as a higher status often gives access to better mates, partners, or resources. ${ }^{1}$ Firms care about how other market parties perceive them, because this affects their access to capital and business opportunities. If working with the best suppliers of goods and services is vital to the success of a company, then firms must carefully scrutinize other companies that they consider working with. In such a context, appearing a better or more reliable supplier is crucial for winning a contract, and this makes signaling and carefully controlling the observable behavior of the company a common element of business life (see, e.g., facade building in banking and insurance, advertising, and public relations efforts). The behavior of individuals or companies in an auction setting is no less prone to interpretation by outside parties looking for clues about how this individual or company is faring, and signaling is therefore documented to matter in, for example, art or charity auctions as well as in a more generic industrial or financial context.

This is an open access article under the terms of the Creative Commons Attribution License, which permits use, distribution and reproduction in any medium, provided the original work is properly cited.

(C) 2020 The Authors. Journal of Economics \& Management Strategy published by Wiley Periodicals LLC 
Mandel (2009) distinguishes three main motives for buying art: investment, direct consumption, and signaling. While art serves as an investment, owners can also enjoy its esthetic qualities and the prestige derived from showing it to friends and acquaintances. Mandel (2009) suggests that the two latter motives explain an old puzzle: why art systematically seems to underperform as an investment compared with bonds and equity, especially when taking the high variance of its yields into account. The underperformance of art is particularly important for famous masterpieces (Mei \& Moses, 2002), which likely have a greater signaling value. Similarly, charities often raise funds by auctioning objects provided to them by celebrities. In recent years, an extensive literature has analyzed charity auctions as auctions in which bidders' preferences are altruistic. ${ }^{2}$ However, the predictions of these theoretical contributions were invalidated in a field experiment (Carpenter et al., 2008), while a broad theoretical and empirical literature suggests that signaling and status are important motives for contributions to charities. ${ }^{3}$ Moreover, the very mechanism of auctioning celebrities' belongings seems to exploit signaling motives. Where altruistic donators can get a warm glow from discreet contributions, it takes a unique object and a public event to make donators shine who (also) care about their public image.

Finally, the public behavior of any sizable firm is under constant scrutiny by market analysts and other market parties. A firm's performance in an auction, irrespective of whether it won or lost the auction, is informative to outsiders trying to judge, for example, its profitability, financial situation, strategy, or management quality. In these auctions, bidders not only care about their payment and about winning the object, but also about what the auction outcome reveals about their type to outsiders. These inferences about the individual qualities of a bidder depend on the outcome and format of the auction, and in turn affect the equilibrium bidding strategies and thus the outcome of the auction.

We study a symmetric independent private value auction with signaling. A single and indivisible commodity is allocated by means of an auction to the one out of $n$ bidders who submits the highest bid. Each bidder independently draws a private valuation for the auctioned object according to the same distribution and this valuation is her private information. ${ }^{4}$ The bidders' payoffs consist of a standard and a signaling component. As in the standard auction model, a winner's ex post payoff equals her private valuation for the object minus her payment and a loser's payoff is minus her payment (which is zero as we consider only winner-pay auctions here). In addition, we assume that each bidder also cares about the beliefs of an outside party, the receiver, about her type. The receiver is assumed to observe and use the auction outcome, in casu the identity and payment of the auction's winner, to form beliefs about the private valuation of all bidders. In the above examples, especially in charity and art auctions, the English design is commonly used, while not yet formally analyzed in the presence of signaling incentives. The second-price auction, although rarely used in practice, is more often studied in all settings because of its common strategic equivalence with the English auction. However, as shown in this text, this equivalence does not exist in the presence of signaling incentives. Therefore, we study how this form of signaling in combination with the details of the auction format affects the inferences by the receiver and thereby the bidding strategies, and eventually also expected revenue.

Because of the combination of a signaling game and an auction in a single game, such that the beliefs of the receiver directly enter the payoff function of the bidders, a general mechanism design approach to this problem is beyond the current state of the art. Auctions with signaling inherit the usual equilibrium multiplicity of signaling games, due to a lack of restrictions on out-of-equilibrium beliefs. Therefore, we restrict out-of-equilibrium beliefs by means of the D1 criterion of Banks and Sobel (1987). The D1 criterion is the most common way of restricting out-of-equilibrium beliefs in signaling games with multiple types, and imposes a monotonicity on out-of-equilibrium beliefs: an out-ofequilibrium bid $b$ is never attributed to a certain bidder type if a higher type bids in equilibrium less than $b$. We show that only fully separating equilibria survive the D1 criterion if the density function characterizing the ex ante distribution of bidders' types is nonincreasing. We elicit conditions for the existence of an essentially unique D1 equilibrium bidding function in the second-price and the English auctions. This analysis is provided through the "button auction," one of the many formalizations of the English auction. Then, we show that for a finite number of bidders, the second-price auction outperforms the button auction in terms of expected revenues. This strict revenue ranking is due to the different amounts of information available to the receiver and the bidders in the two auction formats. We consider the minimal information button auction, in which bidders only observe whether two or more bidders are still active in the auction. The reason is this minimal information setting remains closest to the second-price auction.

In a fully separating equilibrium, the winner's payment imposes a lower bound on the receiver's beliefs about the winner's type in the second-price auction and button auction. This will be shown to induce the lowest types in both auctions to bid strictly above their value in equilibrium and can also induce the highest types to also bid strictly more than in the case without signaling. In addition, the presence of an increasing price (clock) in the button auction weakens bidders' incentives to overbid their true valuation for signaling purposes, compared with the second-price sealed-bid auction. 
Finally, to provide a better understanding of how the content of revealed information matters for the bidders' strategic behavior, we compare our results to the cases in which (i) the winner's identity and her bid, (ii) only the winner's identity, and (iii) all bids and bidders' identities are revealed. These three different disclosure policies have been previously analyzed by Giovannoni and Makris (2014). We show that if the auctioneer can decide, he would prefer to use a second-price auction and to reveal the winner's identity and her payment rather than her bid, or to use an English auction. Yet, revealing only the winner's identity is better in terms of revenue than to also disclose the winner's payment. While revealing all bids and bidders' identity leads to the highest expected revenue for a sufficiently large number of bidders, this relies on some conditions on the equilibrium existence which is not fulfilled for some common distributions.

Signaling in auctions had been studied by at least two strains of theoretical literature. The closest to our analysis is models of information transmission in auctions in function of an aftermarket.

Haile (2003) examines how bidders' incentives for signaling their type in function of a resale auction, in which the winner can resell the item to a loser, depend on the auction formats and information assumptions. He shows that the revenue equivalence may not hold. Goeree (2003) studies oligopolists' bidding for a single-license patent on a cost reducing technology. Each oligopolist has private information about the cost reduction which winning the patent would imply for her firm and other oligopolists try to infer the winner's production cost reduction from the auction outcome to determine their strategies in the aftermarket Cournot competition game. However, Goeree's setting and results are in several respects different from ours. First, Goeree (2003) assumes that the receiver (the other oligopolists) observes the winner's bid, rather than her payment. Second, the structure of the aftermarket imposes a single crossing condition on the winning bidder's payoffs in Goeree (2003): higher types benefit more from an improvement in the receiver's beliefs. And third, in Goeree (2003) only the winning bidder cares about the receiver's inference. Together, these three assumptions imply that Goeree (2003) obtains an expected revenue equivalence of the first-price, second-price, and English auctions.

In a setting similar to Goeree (2003), Katzman and Rhodes-Kropf (2008) show that the auctioneer's announcement policy of bids can change the auction's revenue and efficiency, while Das Varma (2003) elicits conditions for equilibrium existence for a first-price auction with an aftermarket with linear demand functions and Cournot or Bertrand competition. Molnar and Virag (2008) investigate the optimal mechanism and show how the shape of the bidder's profit function w.r.t. the outside observer's inferences affects an auctioneer's revenue maximizing information treatment. Moreover, assuming as Goeree (2003) only the winning bidder is affected by the receiver's inference, Liu (2012) analyzes takeovers through an ascending auction, and shows how the winner's bidding strategy can signal the firm's posttakeover value to the market.

Giovannoni and Makris (2014) study the impact of different disclosure policies in standard independent private value takeover auctions with signaling to an aftermarket. ${ }^{5} \mathrm{~A}$ firm's private valuation is interpreted by a postauction jobmarket for managers as a signal of its manager's ability to extract revenue from an acquisition. The aftermarket observes the winner's identity, a set of bids and the identities of the bidders who submitted those revealed bids. The set of bids revealed can be: no bids, all bids, the highest bid, or the second-highest bid. The information policy closest to ours is revealing the second-highest bid. In Giovannoni and Makris' analysis of the second-price auction also the identity of the second-highest bidder gets revealed. This is an essential different features with our analysis as we reveal only the winner's identity and her payment. That changes the receiver's inferences and the bidding incentives of all potential losers. Finally, Dworczak (2020) studies a setting with abstract aftermarkets in which the mechanism conceals all information and derives conditions under which disclosure of additional information is not profitable.

A second strain of literature studies signaling to other bidders in dynamic auctions. Avery (1998) shows that bidders may use 'jump bids' in the English auction to signal a high valuation to scare away competing bidders, thus decreasing the auction's expected revenue and breaking expected revenue equivalence. Hörner and Sahuguet (2007) compare in a dynamic auction context jump bids and cautious bids as strategic signals about private valuation towards other bidders. Finally, this paper studies how an auctioneer can extract different rents from agents seeking to signal their type to an uninformed party through the auction mechanism, and thus relates to a larger literature about the supply of signaling mechanisms by a profit-maximizing monopolist (see, e.g., Rayo, 2013).

The paper is organized as follows. Section 2 introduces the formal setting and equilibrium concept. Sections 3 and 4 , respectively, characterize the D1 perfect Bayesian equilibria (PBE) of the second-price and the English auctions. The expected revenues of these auctions are compared in Section 5. Section 6 provides a comparison with other information disclosure policies (winner's identity and her bid, only winner's identity, and all bids and bidders' identities). Section 7 concludes. All proofs are collected in Appendix A. 


\section{2 | FORMAL SETTING}

Consider $n$ bidders, indexed $i$, competing for a single object which is allocated through an auction to the highest bidder. Bidder $i$ 's valuation for the object (her 'type') is denoted $V_{i}$, and is assumed i.i.d. and drawn according to a $\mathcal{C}^{2}$ distribution function $F$ with support on $[\underline{v}, \bar{v}] \subset \mathbb{R}_{+}$. Let $f \equiv F^{\prime}$ denote the density function. Bidder $i$ 's realization of $V_{i}$, denoted $v_{i}$, is her private information, but the number of bidders and the distribution $F$ are common knowledge.

To participate in the auction, a bidder submits a nonnegative bid. As all bidders share the same beliefs about the other bidder's valuations, they are assumed to follow a symmetric bidding strategy $\beta:[\underline{v}, \bar{v}] \rightarrow \mathbb{R}_{+}{ }^{6}$ Let $\boldsymbol{b}=\boldsymbol{\beta}(\boldsymbol{v})$ denote the vector of bids given a vector of valuations $\boldsymbol{v}$, with $b_{i}$ the effective bid of $i$ th bidder. An auction mechanism maps a vector of bids $\boldsymbol{b}$ to a winner, denoted $i^{\star}$, and vector of payments $\boldsymbol{p}$. We assume a fair tie breaking in case of multiple highest bids. ${ }^{7}$

Besides the auction's outcome, bidders also care about the beliefs of an uninformed party, the receiver, about their type. This receiver can represent, for example, the general public or press, business contacts or acquaintances of the bidder or experts related to the object sale. The receiver is assumed to observe the auction's winner and her payment $\left(i^{\star}, p_{i^{\star}}\right)$. This either represents a scenario in which the winner and her payment are reported in media outlets, or it reflects a distinction between a payment being 'hard' verifiable evidence, and claims of bids being 'soft' information, which is difficult to verify. Moreover, revealing the winner's identity and her payment is relevant with many economic situations in practice. For example, the Hospices de Beaune, ${ }^{8}$ in Burgundy (France), organizes a yearly wine auction for charity, in which the winner's identity and her payment are publicly revealed. In many art auctions, that is, in which signaling matters, the auction's outcome is available in the press the day after. A directive from the European Union on public procurement stipulates that this very information must be contained in a contract award notice. ${ }^{9}$ We keep this information assumption constant throughout both the second-price and the English auctions to ensure comparability. The receiver's beliefs, denoted $\mu$, are a probability distribution over the type space, such that $\mu_{i}\left(v \mid\left(i^{\star}, p_{i^{\star}}\right)\right)$ is the probability of bidder $i$ being of valuation type $v$ given $\left(i^{\star}, p_{i^{\star}}\right)$. Let $\mu\left(\boldsymbol{v} \mid\left(i^{\star}, p_{i^{\star}}\right)\right)$ then be a probability distribution over vectors of valuations $\boldsymbol{v}$ given $\left(i^{\star}, p_{i^{\star}}\right)$. The receiver's beliefs are (Bayesian) consistent with a bidding strategy $\beta$ if ${ }^{10}$

$$
\mu\left(\boldsymbol{v} \mid\left(i^{\star}, p_{i^{\star}}\right)\right)=\frac{\operatorname{Pr}\left(i^{\star}, p_{i^{\star}} \mid \boldsymbol{\beta}(\boldsymbol{v})\right) \prod_{i} f\left(v_{i}\right)}{\int \operatorname{Pr}\left(i^{\star}, p_{i^{\star}} \mid \boldsymbol{\beta}\left(\boldsymbol{v}^{\prime}\right)\right) \prod_{i} f\left(v_{i}^{\prime}\right) \boldsymbol{d} \boldsymbol{v}^{\prime}} .
$$

The utility of bidder $i$, given an auction outcome $\left(i^{\star}, \mathbf{p}\right)$, consists of two parts. The first part is standard: the valuation for the object for the winner of the auction, minus the payment (which is here zero for all losers). The second part is the expected value of the receiver's beliefs about bidder $i$ 's type given $\left(i^{\star}, p_{i^{\star}}\right)$, denoted $\mathbb{E}\left(V_{i} \mid \mu_{i}\left(V_{i} \mid i^{\star}, p_{i^{\star}}\right)\right)$ :

$$
u_{i}\left(v_{i}, p_{i} \mid \mu_{i}\right)= \begin{cases}v_{i}-p_{i}+\mathbb{E}\left(V_{i} \mid \mu_{i}\left(V_{i} \mid i^{\star}, p_{i^{\star}}\right)\right) & \text { for winner } i=i^{\star}, \\ \mathbb{E}\left(V_{i} \mid \mu_{i}\left(V_{i} \mid i^{\star}, p_{i^{\star}}\right)\right) & \text { for loser } i \neq i^{\star}\end{cases}
$$

This utility function either represents a psychological game, in which bidders care directly about the receiver's beliefs, as humans care about the good opinion of others, or is reduced form of a game in which the receiver chooses an action given her beliefs, while the bidders care about this action. ${ }^{11}$ In the latter case, an explicit analysis of the receiver's problem is easily integrated, but does not add much. Although somewhat restrictive, this linear payoff structure is the most natural benchmark case to study the role of signaling in auctions, because it guarantees a tractable solution and ensures that the auction formats under consideration are expected revenue equivalent without signaling. ${ }^{12}$

We study the symmetric PBE of this auction game with signaling. A PBE is then described by a pair bidding strategy and beliefs $(\beta, \mu)$ such that:

1. The bidding function $\beta$ maximizes expected utility for all $v$, given that all other bidders play $\beta$ and given the receiver's beliefs $\mu$.

2. The receiver's beliefs $\mu$ are Bayesian consistent with the bidding function $\beta$, as in (1).

Because this equilibrium concept imposes no restrictions on out-of-equilibrium beliefs, that is, how the receiver interprets auction outcomes which should never occur on the equilibrium path, we face the usual equilibrium multiplicity of signaling games. Therefore, we use the D1 criterion of Banks and Sobel (1987), which refines the set of equilibria by restricting out-of-equilibrium beliefs. The D1 criterion restricts out-of-equilibrium beliefs by considering 
which bidder types are more likely to gain from an out-of-equilibrium bid, compared with their equilibrium expected utility. More precisely, if the set of beliefs for which a bidder gains from a deviation to an out-of equilibrium bid $b$ (w.r.t. her equilibrium expected utility) is larger for one bidder type than for another, then the D1 criterion requires out-ofequilibrium beliefs to attribute zero probability the latter type having deviated to $b .{ }^{13}$ The D1 criterion imposes a certain monotonicity on out-of-equilibrium beliefs, which excludes many implausible equilibria.

However, although the D1 criterion typically excludes (semi)pooling PBE in monotonic signaling games on the one hand, and although (semi)pooling strategies are normally easily excluded in canonical auction games with the present preference structure on the other hand, the exercise of excluding (semi)pooling equilibria by means of the D1 criterion is less obvious when both games are combined into an auction with signaling.

\section{I SECOND-PRICE AUCTION}

In this section, we derive the essentially unique D1 PBE bidding strategies for the second-price auction, in which the winner pays the second-highest bid. Because the receiver only observes the identity and payment of the winner, the latter only allows her to bind the set of possible bids of the winner from below and the set of possible bids of the losers from above. This difference in information available to the receiver considerably alters the bidders' expected payoff and equilibrium bidding.

The second-price auction suffers from a multiplicity of equilibria due to insufficient restrictions on out-of-equilibrium beliefs, which is remedied by imposing the D1 criterion. A bidder deviating unilaterally to a bid above the highest equilibrium bid always wins the auction. But such a deviation will not be revealed, because the winner only pays the second-highest bid, which has an equilibrium interpretation. Therefore, bids cannot be constrained from above by possibly implausible out-of-equilibrium beliefs. Out-of-equilibrium beliefs for bids below the minimal equilibrium bid do not affect bidding because such deviations can never be observed by the outside observer, such that implausible out-of-equilibrium beliefs can never constrain equilibrium bidding from below. However, discontinuities in the bidding function at intermediate valuations can be supported by particular out-of-equilibrium beliefs. Such deviations are revealed to the receiver if they constitute the second-highest bid, in which case they fix the inference about all losing bidders, including the deviator.

In what follows, we restrict $F$ to be concave, that is, $f^{\prime}(\cdot) \leq 0$. This condition is proven to be close to a necessary condition for the existence of a fully separating PBE in both the second-price and the English auctions. Note that this condition implies the common log-concavity of $F$ or the nondecreasing hazard rate condition. It neither implies nor is implied by the log-concave density condition imposed by Goeree (2003). ${ }^{14}$ This condition implies that only fully separating equilibria survive the D1 criterion. ${ }^{15}$ Although restrictive, this condition is likely satisfied if we believe that only the top end of, for example, the income distribution participates in art or charity auctions.

Lemma 1. If $f^{\prime}(\cdot) \leq 0$ and $n \geq 3$, then $\beta^{\prime}(\cdot)>0$ in any $D 1 P B E$ of the second-price auction.

We now proceed step by step to construct the problem of a $v$-type bidder choosing which type $\tilde{v}$ to mimic in the second-price auction. As before, a strictly increasing bidding function implies that a type-v bidder choosing the $\tilde{v}$-type's equilibrium bid wins with probability $F^{n-1}(\tilde{v})$. In this case, her payoff is

$$
v-\frac{1}{F^{n-1}(\tilde{v})} \int_{\underline{v}}^{\tilde{v}} \beta(x) d F^{n-1}(x)+\frac{1}{F^{n-1}(\tilde{v})} \int_{\underline{v}}^{\tilde{v}} \frac{\int_{x}^{\bar{v}} y d F(y)}{1-F(x)} d F^{n-1}(x) .
$$

The second term is the expected payment if $\beta(\tilde{v})$ is the winning bid and the third term is the receiver's expected inference about a winner of valuation $\tilde{v}$. If the second-highest bidder is of type $x$, then the inference about the winner is $\frac{\int_{x}^{\tilde{v}} y d F(y)}{1-F(x)}$. But because the second-highest bid is unknown to the bidder, the third term takes the expectation over the second-highest bid.

Second, with probability $(n-1) F^{n-2}(\tilde{v})(1-F(\tilde{v}))$ bid $\beta(\tilde{v})$ is the second-highest bid. In this case, the receiver's inference about any losing bidder is

$$
\frac{\tilde{v}}{n-1}+\frac{n-2}{n-1} \frac{\int_{\underline{v}}^{\tilde{v}} x d F(x)}{F(\tilde{v})}
$$


as one of the $n-1$ losers has valuation $\tilde{v}$ while the $n-2$ others' valuations are weakly lower than $\tilde{v}$. Finally, with probability $1-F^{n-1}(\tilde{v})-(n-1) F^{n-2}(\tilde{v})(1-F(\tilde{v}))$, a type- $\tilde{v}$ bidder is neither the highest nor second-highest bidder. For this case, a bidder forms an expectation over the second-highest bid to assess the receiver's expected inference about the losing bidders.

The expected utility of a valuation $v$ bidder choosing type-v's bidding strategy is then

$$
\begin{aligned}
& \int_{\underline{v}}^{\tilde{v}}(v-\beta(x)) d F^{n-1}(x)+\int_{\underline{v}}^{\tilde{v}} \frac{\int_{x}^{\bar{v}} y d F(y)}{1-F(x)} d F^{n-1}(x) \\
& +(n-1) F^{n-2}(\tilde{v})(1-F(\tilde{v}))\left(\frac{\tilde{v}}{n-1}+\frac{n-2}{n-1} \frac{\int_{\underline{v}}^{\tilde{v}} x d F(x)}{F(\tilde{v})}\right) \\
& +\int_{\tilde{v}}^{\bar{v}}\left(\frac{y}{n-1}+\frac{n-2}{n-1} \frac{\int_{\underline{v}}^{y} x d F(x)}{F(y)}\right) d\left((n-1) F^{n-2}(y)-(n-2) F^{n-1}(y)\right) .
\end{aligned}
$$

The first-order condition is

$$
\begin{aligned}
\beta(\tilde{v})\left(F^{n-1}(\tilde{v})\right)^{\prime}= & v\left(F^{n-1}(\tilde{v})\right)^{\prime}+\frac{\int_{\tilde{v}}^{\bar{v}} x d F(x)}{1-F(\tilde{v})}\left(F^{n-1}(\tilde{v})\right)^{\prime} \\
& +F^{n-2}(\tilde{v})(1-F(\tilde{v}))\left(1+(n-2) \frac{\tilde{v} f(\tilde{v}) F(\tilde{v})-f(\tilde{v}) \int_{\underline{v}}^{\tilde{v}} x d F(x)}{F^{2}(\tilde{v})}\right) \\
& +\left((n-2) f(\tilde{v}) F^{n-3}(\tilde{v})-(n-1) f(\tilde{v}) F^{n-2}(\tilde{v})\right)\left(\tilde{v}+(n-2) \frac{\int_{\underline{v}}^{\tilde{v}} x d F(x)}{F(\tilde{v})}\right) \\
& -\left((n-2) f(\tilde{v}) F^{n-3}(\tilde{v})-(n-2) f(\tilde{v}) F^{n-2}(\tilde{v})\right)\left(\tilde{v}+(n-2) \frac{\int_{\underline{v}}^{\tilde{v}} x d F(x)}{F(\tilde{v})}\right)
\end{aligned}
$$

After dividing both sides by $\left(F^{n-1}(\tilde{v})\right)^{\prime}=(n-1) F^{n-2}(\tilde{v}) f(\tilde{v})$, imposing $\tilde{v}=v$ and simplifying, we obtain

$$
\begin{aligned}
\beta(v)= & v+\frac{\int_{v}^{\bar{v}} x d F(x)}{1-F(\tilde{v})}+\frac{1-F(v)}{f(v)(n-1)}\left(1+f(v) \frac{n-2}{F(v)}\left(v-\frac{\int_{\underline{v}}^{v} x d F(x)}{F(v)}\right)\right) \\
& -\frac{1}{n-1}\left(v+(n-2) \frac{\int_{\underline{v}}^{v} x d F(x)}{F(v)}\right) \\
\equiv & v+\Psi(v) .
\end{aligned}
$$

The essentially unique D1 PBE bidding function for the second-price auction is then characterized by the following proposition.

Proposition 1. If either $n \geq 4$ and $f^{\prime}(\cdot) \leq 0$ or $n=3$ and $f^{\prime}(\cdot)<0$, then an essentially unique second-price auction D1 PBE exists, and its bidding strategy is

$$
\beta(v)=\frac{n-2}{n-1} \frac{v-\mathbb{E}(V \mid V \leq v)}{F(v)}+\mathbb{E}(V \mid V \geq v)+\frac{1-F(v)}{(n-1) f(v)},
$$


with $\lim _{v \rightarrow \underline{v}} \beta(v)=\mathbb{E}(V)+\frac{n}{n-1} \frac{1}{2 f(\underline{v})}$ and $\lim _{v \rightarrow \bar{v}} \beta(v)=\bar{v}+\frac{n-2}{n-1}(\bar{v}-\mathbb{E}(V))$.

The qualification 'essential' reflects that the equilibrium bidding function is undetermined at both extremes of the type space. If $\beta^{\prime}(\cdot)>0$, then a $\underline{v}$ type has the highest or second-highest bid with zero probability, such that all bids in $\left[0, \mathbb{E}(V)+\frac{n}{n-1} \frac{1}{2 f(\underline{\underline{\nu}})}\right]$ are in equilibrium payoff equivalent. On the other hand, for finite $n$ a $\bar{v}$ type wins with probability 1 and does not pay her own bid, such that all bids weakly above $\lim _{v \rightarrow \bar{v}} \beta(v)$ are in equilibrium payoff equivalent. However, the D1 equilibrium bidding function is uniquely determined on $(\underline{v}, \bar{v})$. Remark that the limit of the equilibrium bidding function at $\underline{v}$ lies strictly above the average valuation for the object. Indeed if a very low valuation type wins the auction, the winner is inferred as slightly higher than an $\mathbb{E}(V)$ type by the receiver, while all losers are inferred almost as $\underline{v}$ types, because the second-highest bidder's type is below the winner's valuation. Therefore, the lowest types bid at least their valuation $\underline{v}$ plus the difference in inference by the receiver $\mathbb{E}(V)-\underline{v}$ in equilibrium.

By reflecting the second-highest bid, the winner's payment only imposes a lower bound on the receiver's expected beliefs about the winner's type. This incites the low valuation types to bid considerably above their valuation. The reason is that if they win the auction, they pay the bid of an even lower type, while the receiver's expected inference about the winner is just above the ex ante average valuation $\mathbb{E}(V)$ and the expected inference about the losers is close to the lowest possible valuation. Moreover, the higher the bidder's type is, the lower the incentives are to bid above her valuation, because the difference in the expected inferences about the winner and the losers decreases with $v$. Therefore, an inspection of the bidding function in (2) shows how a type- $v$ bidder inflates her bid by $\Psi(v)$ compared with the standard second-price auction without signaling. A further comparison with the equilibrium bidding function of the English auction in Section 4 will provide additional intuitions for the second-price D1 PBE bidding function.

Note that in the second-price auction, there is no fully separating equilibrium with two bidders, and even not with three bidders if the density $f$ is constant over some interval of the support. In the following example with a uniform distribution on $[0,1]$, we comment on this nonexistence of an equilibrium with two or three bidders. However, this nonexistence result relies on the importance of the bidders' sensitivity to signaling concerns. In this example, we introduce a scalar $\gamma$, as discussed in footnote 12, to measure the relative importance of the receiver's inference in the bidder's payoff function. It shows that the equilibrium for two bidders does not exist for $\gamma>2 / 3$ and provides some comparative statics on the relative importance of the bidders' sensitivity for signaling.

Example 1 (Uniform on $[0,1]$ and bidders' sensitivity $\gamma$ to signaling). Consider an example in which the receiver's expected inference is weighted by a scalar $\gamma$ in the bidder's payoff function:

$$
u_{i}\left(v_{i}, p_{i} \mid \mu_{i}\right)= \begin{cases}v_{i}-p_{i}+\gamma \mathbb{E}\left(V_{i} \mid \mu_{i}\left(V_{i} \mid i^{\star}, p_{i^{\star}}\right)\right) & \text { for winner } i=i^{\star}, \\ \gamma \mathbb{E}\left(V_{i} \mid \mu_{i}\left(V_{i} \mid i^{\star}, p_{i^{\star}}\right)\right) & \text { for loser } i \neq i^{\star},\end{cases}
$$

with $\gamma \geq 0$ measuring the relative bidders' sensitivity to signaling concerns. For $F$ uniform on $[0,1]$, the expected payoff of a $v$-type bidder imitating a $\tilde{v}$ type is

$$
\begin{aligned}
& v_{i} \tilde{v}^{n-1}-(n-1) \int_{0}^{\tilde{v}} x^{n-2} \beta(x) d x+\gamma \frac{n-1}{2} \tilde{v}^{n-1}\left(\frac{1}{n-1}+\frac{\tilde{v}}{n}\right) \\
& \quad+\gamma(n-1) \tilde{v}^{n-2}(1-\tilde{v})\left(\frac{n-2}{n-1} \frac{\tilde{v}}{2}+\frac{\tilde{v}}{n-1}\right) \\
& \quad+\gamma\left(1-\tilde{v}^{n-1}-(n-1) \tilde{v}^{n-2}(1-\tilde{v})\right) \frac{\int_{\tilde{v}}^{1}\left(\frac{x}{n-1}+\frac{n-2}{n-1} \frac{x}{2}\right) d\left((n-1) x^{n-2}-(n-2) x^{n-1}\right)}{\left(1-\tilde{v}^{n-1}-(n-1) \tilde{v}^{n-2}(1-\tilde{v})\right)} .
\end{aligned}
$$

The D1 PBE bidding function is

$$
\beta(v)=v+\gamma \frac{2 n-1-(n+1) v}{2(n-1)} .
$$


Signaling concerns cause overbidding compared with a standard auction by an amount $\gamma \frac{2 n-1-(n+1) v}{2(n-1)}$. Unsurprisingly, $\gamma=0$ leads to the standard second-price auction without signaling. $\gamma=1$ corresponds to the case fully investigated in this section, in which the outcome of the auction and the receiver's beliefs receive the same weight in the payoff function. Remark that the D1 PBE does not exist for any $\gamma \geq \frac{2(n-1)}{n+1}$. Every increase of $\gamma$ in $\left[0, \frac{2(n-1)}{n+1}\right)$ gives more importance to the receiver's expected inference and this leads to a more aggressive bidding. The bidding function also shows that the overbidding compared with the standard auction without signaling decreases with a bidder's type $v$.

If $n=2$, the receiver can pinpoint the losing bidder's type $v$ in equilibrium, while the winner's type can be narrowed down only to the average between the valuation of the loser and the maximum valuation 1 , that is, the expected inference for $n=2$ is

$$
\gamma \tilde{v}\left(\frac{1}{2}+\frac{\tilde{v}}{4}\right)+\gamma(1-\tilde{v}) \tilde{v}=\gamma \frac{3 \tilde{v}}{4}(2-\tilde{v})
$$

For two bidders, the receiver's inference increases more with $\tilde{v}$ if a bidder loses, but the probability of losing decreases with $\tilde{v}$, such that the marginal effect of $\tilde{v}$ on the receiver's expected inference, that is, $\gamma \frac{3}{2}(1-\tilde{v})$, decreases with $\tilde{v}$ at a constant rate $\frac{3}{2}$. For any value of $\gamma>\frac{2}{3}$, this decreases more than offsets the higher valuation types' incentives to bid strictly more than lower types, which in turn breaks down the existence of a D1 PBE. At $n=3$ both these effects cancel out exactly for $\gamma=1$. Thus, we have no D1 equilibrium bidding function for $n=2$ and $\gamma>\frac{2}{3}$, and for $n=3$ and $\gamma \geq 1$.

A similar logic about the existence of a D1 PBE applies if $f$ is constant over an interval in the support of a more general distribution function, such that Proposition 1 requires either that $n \geq 4$ and $f^{\prime}(\cdot) \leq 0$ or that $n=3$ and $f^{\prime}(\cdot)<0$.

\section{4 | ENGLISH AUCTION}

An important reason for the popularity of the second-price auction among auction theorists is its common strategic equivalence with the English auction, which is more frequently used in reality. However, this equivalence ceases to exist in the presence of signaling. This result can be surprising, because the introduction of other externalities, such as financial externalities in charity auctions (e.g., Engers \& McManus, 2007), did not break up the strategic equivalence.

The English auction can be studied in various formalizations. We consider a minimal information "button auction" (see, e.g., Milgrom, 2004; Milgrom \& Weber, 1982), in which the auctioneer lets the price continuously increase on a price clock. Each bidder chooses when to exit the auction by releasing a button, and such exit is irrevocable. The last bidder holding her button wins, and pays the price fixed when the second-highest bidder released her button. Bidders only observe whether two or more bidders are still pushing their button or not, and the latter implies that the auction has a winner. This minimal information setting remains closest to the second-price auction, as bidders can learn little about the other bidders' valuations during the auction. We maintain the assumption that the receiver only observes the identity and the payment of the winner. This keeps the information that the receiver disposes of constant throughout the different auction formats to ensure the comparability of the results. ${ }^{16}$ Remark that a strict ranking of the revenues between the second-price auction and this minimal information button auction would explain the role plays by dynamic features. Therefore we could also conclude for the revenue comparison between the second-price auction and the button auction (without information restriction on the bidders' exit).

In this auction, each bidder has to decide on each moment (or price) whether to stay in or to exit. Note then that in equilibrium, the exit price is increasing with $v$ because the prospects in terms of inference by the receiver at a certain price are identical for different types, while the lower-type values winning the auction strictly less. Again, we restrict out-of-equilibrium beliefs by means of the D1 criterion to avoid the multiplicity of equilibria, and establish that any D1 PBE is fully separating.

Lemma 2. In any $D 1 P B E$, the exit rule $\beta$ is a continuous and strictly increasing function of $v$.

If the bidding strategy (i.e., exit price) is strictly increasing with type and as the winner pays the price posted when the second-highest bidder left the auction, then the second-highest bidder fixes the payoff of all bidders. 
Since bidders do not observe previous exits by lower valuation bidder, the latter's strategy does not affect equilibrium bidding. Of course, a bidder does not know whether she has the second-highest valuation, but she optimizes her strategy as if this was the case. A type- $v$ bidder then leaves the auction when the price hits the bid of a $\tilde{v}$ type, such that

$$
v-\beta(\tilde{v})+\frac{1}{1-F(\tilde{v})} \int_{\tilde{v}}^{\bar{v}} x d F(x)=\frac{\tilde{v}}{n-1}+\frac{n-2}{n-1} \frac{\int_{\underline{v}}^{\tilde{v}} x d F(x)}{F(\tilde{v})} .
$$

The left-hand side (LHS) of (3) is the payoff a type- $v$ bidder gets if she wins at price $\beta(\tilde{v})$, while the right-hand side (RHS) is a loser's payoff, if she releases the button at price $\beta(\tilde{v})$ with only two bidders left. This exit rule defines a unique equilibrium bidding function of the second-highest valuation type, which determines the auction price. This is equivalent to having at each price $b$ type $\beta^{-1}(b)$ leaving the auction, such that the optimal exit price of type $v$ satisfies

$$
v-b+\frac{1}{1-F\left(\beta^{-1}(b)\right)} \int_{\beta^{-1}(b)}^{\bar{v}} x d F(x)=\frac{\beta^{-1}(b)}{n-1}+\frac{n-2}{n-1} \frac{\int_{\underline{v}}^{\beta^{-1}(b)} x d F(x)}{F\left(\beta^{-1}(b)\right)} .
$$

Note in (4) that the receiver's inference about the winner and about all losers increase with $b$ (or $\tilde{\text { ) }}$. However, the following proposition establishes that in equilibrium the costs of mimicking a higher type in terms of payment increase faster than the benefits in terms of inference, such that this equality establishes the essentially unique D1 equilibrium exit rule for the English auction.

Proposition 2. If $n \geq 3$ and $f^{\prime}(\cdot) \leq 0$, then an essentially unique D1 PBE exists for the (minimal information, button) English auction, and its exit rule is

$$
\beta(v)=\frac{n-2}{n-1}\left(v-\frac{\int_{\underline{v}}^{v} x d F(x)}{F(v)}\right)+\frac{\int_{v}^{\bar{v}} x d F(x)}{1-F(v)},
$$

with $\lim _{v \rightarrow \underline{v}^{+}} \beta(v)=\mathbb{E}(V)$ and $\lim _{v \rightarrow \bar{v}} \beta(v)=\bar{v}+\frac{n-2}{n-1}(\bar{v}-\mathbb{E}(V))$.

As for the second-price auction, the winner's payment only imposes a lower bound on the receiver's expected beliefs about the winner's type, and this again induces the low valuation types to bid significantly above their valuation because the receiver's expected inference about the winner is just above the ex ante average valuation $\mathbb{E}(V)$ and the expected inference about the losers is close to the lowest possible valuation. In the English auction, all bidders increase their bid compared with a standard auction without signaling by a term $\frac{1}{1-F(v)} \int_{v}^{\bar{v}} x d F(x)-\left(\frac{v}{n-1}+\frac{n-2}{n-1} \frac{\int_{v}^{v} x d F(x)}{F(v)}\right)$, because of the signaling concerns.

Given the optimal exit strategy of a winner in the English auction, the second-price and the English auctions are equivalent in terms of information for the receiver. A closer comparison of equilibrium bidding in both auctions can therefore also further clarify the equilibrium in the second-price auction. When comparing the equilibrium bidding functions of the second-price and the English auctions, we note both are identical up to the two following additional terms in the former:

$$
\frac{1-F(v)}{F(v)} \frac{n-2}{n-1}\left(v-\frac{\int_{\underline{v}}^{v} x d F(x)}{F(v)}\right)+\frac{(1-F(v))}{(n-1) f(v)}>0,
$$

which vanish for $v \rightarrow \bar{v}$. A closer inspection of (2) shows that these two additional terms, the third RHS term in (2), reflect the effect on the receiver's expected inference about all the losing bidders of a marginally increased bid for a given probability of being the second-highest bidder. 
The main difference between the second-price and the English auctions is that in the latter, the set of possible secondhighest bids is bounded from below by the increasing price clock. If the English auction has no winner at price $b$, then all active bidders can take it as a given that the second-highest bid is at least $b$, and that the receiver's expected inference about the winner will be bounded from below by $\beta^{-1}(b)$. This lower bound on the second-highest bid also bounds the receiver's expected inference about the losers from below. Therefore, each bidder just compares at each price her payoff as a winner and as a loser with the second-highest bid, and quits if both are equal. If she turns out not being the second-highest bidder, then the payoff of losing certainly exceeds her payoff of winning. As such, (5) means that an active bidder exits when the price equals her valuation plus the difference between the receiver's inference about the winner and a loser if this exit price was the second-highest bid.

In the second-price auction, no increasing price clock bounds the second-highest bid. First, in case of winning, a high valuation bidder must consider the possibility of paying the bid of a very low valuation bidder when winning, and consequently being inferred as the expected value of any type above the latter by the receiver. The benefits of the potentially lower payment are compensated by the low inference by the receiver. In the case of losing the auction, a bidder can bound the receiver's inference about her type from below by means of her own bid. Compared with the English auction, this provides an additional marginal benefit to bidding in the second-price auction, which disappears as $v$ approaches $\bar{v}$ (for which the probability of losing goes to zero).

Example 2 (Uniform on $[0,1]$ and bidders' sensitivity to signaling $\gamma$ ). As in Example 1, consider a case in which the receiver's expected inference is weighted by a scalar $\gamma \geq 0$ in the bidder's payoff function, and $F$ represents the uniform distribution on the unit interval. Equality (3) then becomes

$$
v-\beta(\tilde{v})+\gamma \frac{1+\tilde{v}}{2}=\gamma \frac{\tilde{v}}{n-1}+\gamma \frac{n-2}{n-1} \frac{\tilde{v}}{2}
$$

which implies the D1 PBE exit rule

$$
\beta(v)=v+\frac{\gamma}{2}-\gamma \frac{v}{2(n-1)}
$$

Signaling affects bidding to some extent as in the second-price auction. The case $\gamma=0$ corresponds to the standard English auction without signaling, and $\gamma=1$ to the case fully investigated in this section, in which bidders are as sensitive for the outcome of the auction as for the receiver's beliefs. Remark that the D1 PBE does not exist for any $\gamma \geq 2(n-1)$. An increase of $\gamma$ in [0,2(n-1)) leads to a more aggressive bidding behavior. A comparison of the overbidding in the present example and Example 1 shows strictly lower overbidding in the English auction than that in the second-price auction for all values of $\gamma$, but this difference can be seen to reduce to zero as the bidder's type tends to the upper bound 1.

\section{I EXPECTED REVENUE COMPARISON}

We now compare the expected revenue of the two auction designs analyzed so far. Let $\mathrm{ER}^{\mathrm{II}}$ and $\mathrm{ER}^{\mathrm{E}}$ denote the expected revenue, respectively, of the second-price and the English auctions. The following proposition shows that for finite $n$, we obtain a strict ranking in terms of expected revenues of the English and the second-price auctions.

Proposition 3 (Expected revenue ranking). If $f^{\prime}(\cdot) \leq 0$ and $n \geq 4$, and if $n$ is finite, then in the D1 PBE

$$
\mathrm{ER}^{\mathrm{II}}>\mathrm{ER}^{\mathrm{E}}
$$

The following example illustrates this strict expected revenue ranking for $F$ being the uniform distribution. 


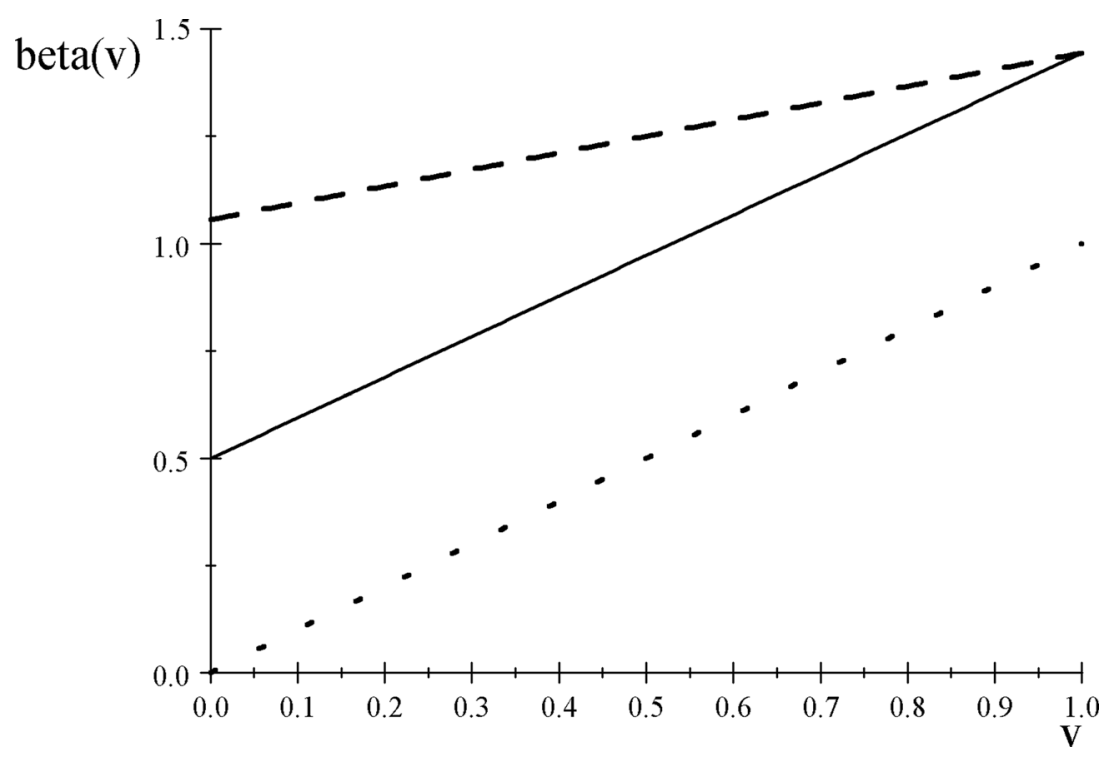

FIGURE 1 The D1 PBE bidding for $U[0,1]$ with $n=10$, for the English (solid) and the second-price (dashed) auctions with signaling, and without signaling (dots)

Example 3 (Uniform on $[0,1]$ ). For the uniform distribution on $[0,1]$, Figure 1 represents the D1 PBE bidding functions for the auction formats studied so far. The expected revenue of the second-price and the English auctions is then

$$
\begin{aligned}
\mathrm{ER}^{\mathrm{II}} & =\frac{n(n-1)}{2(n-1)} \int_{0}^{1}(2 n-1+(n-3) v)\left(v^{n-2}-v^{n-1}\right) d v \\
& =\frac{3(n-1) n+2}{2\left(n^{2}-1\right)}
\end{aligned}
$$

and

$$
\mathrm{ER}^{\mathrm{E}}=\frac{1}{2}+\frac{n(2 n-3)}{2}\left(\int_{0}^{1} v^{n-1} d v-\int_{0}^{1} v^{n} d v\right)=\frac{1}{2}+\frac{(2 n-3)}{2(n+1)}
$$

such that the second-price auction outperforms the English auction,

$$
\mathrm{ER}^{\mathrm{II}}-\mathrm{ER}^{\mathrm{E}}=\frac{2 n+1}{2(n-1)(n+1)}>0
$$

This strict ranking in terms of expected revenues reflects the differences in the information that is available to the bidders in the two auction formats. The absence of a price clock in the sealed-bid second-price auction implies an additional marginal benefit of a higher bid in comparison with the English auction: one's bid constrains the receiver's expected inference in case of losing the auction from below. Because of this additional effect, the equilibrium bids are strictly lower in the English auction than those in the second-price auction for all bidders with a valuation strictly below the upper bound $\bar{v}$. Since the winner pays the bid of the second-highest bidder in both auctions, the second-price auction dominates the English auction in terms of expected revenue.

However, note that expected revenue equivalence is restored asymptotically for $n$ going to infinity. Let $\beta^{\text {II }}(\cdot)$ and $\beta^{\mathrm{E}}(\cdot)$ denote the equilibrium bidding functions of the second-price and the English auctions. In the limit, the bid of the $\bar{v}$ type is identical in all auctions:

$$
\lim _{n \rightarrow+\infty} \lim _{v \rightarrow \bar{v}} \beta^{\mathrm{II}}(v)=\lim _{n \rightarrow+\infty} \lim _{v \rightarrow \bar{v}} \beta^{\mathrm{E}}(v)=2 \bar{v}-\mathbb{E}(V) .
$$


If $n \rightarrow \infty$, both the winner of the auction and the second-highest bidder have type $\bar{v}$ with probability 1 . As such, the $\bar{v}$ type winner pays her own bid in all auctions. In addition, the $\bar{v}$-type's winning bid must make her indifferent between winning and losing, because another bidder with a valuation of almost $\bar{v}$ type would otherwise benefit from outbidding her.

\section{6 | OTHER INFORMATION DISCLOSURE POLICIES}

Our analysis illustrates that the auction format and informational assumptions matter if bidders use the auction outcome for signaling their valuation to an uninformed party. Although the present setting is reflecting the examples presented in the first two sections of this text, a broad variety of alternative settings merit attention. Different informational assumptions can be equally plausible, depending on the particular application one has in mind. Among them, we distinguish three interesting disclosure policies, characterizing different sets of information that the auctioneer can share with the receiver: (i) the winner's identity and her bid, (ii) only the winner's identity, and (iii) all bids and bidders' identities. Note that the second-price auction for these other information settings has been analyzed in Giovannoni and Makris (2014).

\section{1 | Winner's identity and her bid revealed}

In this subsection we compare our results with the case, in which the winner's identity and her bid (instead of her payment) are disclosed to the receiver. We denote $\beta^{\mathrm{II}, \mathrm{B}}$ corresponding bidding function in the second-price auction.

In the second-price auction the winner's type, $v$, is fully revealed to the receiver, as $\beta^{-1}(\beta(v))=v \cdot{ }^{17}$ If the winner's type is known to be $v$, the expectation of a loser's valuation is $\frac{1}{F(v)} \int_{\underline{v}}^{v} x d F(x)$. However, if a $v$ type does not win, she ex ante does not know the winner's valuation (except that it is above $v$ ), such that her expectation of the receiver's inference about a loser is $\frac{\int_{v}^{\bar{v}} \frac{1}{F(y)} \int_{\underline{v}}^{y} x d F(x) d F^{n-1}(y)}{1-F^{n-1}(v)}$. Giovannoni and Makris (2014) analyzed this second-price auction and determined that the fully separating equilibrium is given by

$$
\beta^{\mathrm{II}, \mathrm{B}}(v)=2 v-\mathbb{E}(V \mid V \leq v)+\frac{F(v)}{(n-1) f(v)}
$$

if $F^{n-1}$ is log-concave. ${ }^{18}$ Remark that, if a fully separating equilibrium exists, then the information available for the outside observer when the winner's identity and her bid are revealed is the same in the second-price and the English auctions. Moreover, the receiver's inferences about the winning and losing bidders now only depend on the winner's bid, and not on the second-highest bid. This means that the presence of a price clock does not play the role that it does in the English auction in which the payment is revealed, that is, to constrain the bidder's expectations of the receiver's beliefs about the losing bidders, which causes the divergence in expected revenue between the second-price and the English auctions if the winner's payment is revealed to the receiver. As a result, these two auctions are revenue equivalent under the current information disclosure policy. We denote $\mathrm{ER}^{\mathrm{B}}$ the expected revenue when the winner's bid is revealed.

The following proposition determines that the second-price auction when the winner's payment is revealed instead of her bid yields to a higher expected revenue. If the auctioneer can decide, he will disclose the winner's payment and use a second-price auction. This requires that the conditions for the existence of fully separating equilibrium in the second-price auction in both information settings are fulfilled, that is, $F^{n-1}$ is log-concave and $f$ is decreasing.

Proposition 4 (Winner's payment vs. winner's bid). Assume the conditions for the existence of a fully separating equilibrium are satisfied. If $n \geq 4$, and if $n$ is finite, then in the D1 PBE

$$
\mathrm{ER}^{\mathrm{II}}>\mathrm{ER}^{\mathrm{B}}>\mathrm{ER}^{\mathrm{E}} .
$$

This ranking in terms of expected revenues stems from the differences in information available to the receiver and the bidders. As previously mentioned, revealing the winner's payment imposes a lower bound on the receiver expected 
beliefs about the winner's type, and then generates high incentives for low bidders' type. When the winner's bid is revealed, in contrast, a winning low-type bidder is perfectly pinpointed by the receiver, and therefore has less incentives to bid high. This makes the driving force for a better revenue in the second-price auction when the winner's payment is revealed.

However, the equilibrium bidding function for high types in the second-price when the winner's bid is revealed is strictly higher than that in the English auction when the winner's payment is revealed. The reason is that the gap in terms of the receiver's expected inference between winning and losing is larger. On the one hand, losing $\bar{v}$ types at $\lim _{v \rightarrow \bar{v}} \beta(v)$ are interpreted as $\frac{\bar{v}}{n-1}+\frac{n-2}{n-1} \mathbb{E}(V)$ if the payment is revealed rather than as $\mathbb{E}(V)$ if the winner's bid is revealed. On the other hand, a winning $\bar{v}$ type is in both revealing policy inferred to be a $\bar{v}$ type.

Remark that the bid of the $\bar{v}$ type for $n$ going to infinity is identical in both information settings:

$$
\lim _{n \rightarrow+\infty} \lim _{v \rightarrow \bar{v}} \beta^{\mathrm{II}}(v)=\lim _{n \rightarrow+\infty} \lim _{v \rightarrow \bar{v}} \beta^{\mathrm{II}, \mathrm{B}}(v)=\lim _{n \rightarrow+\infty} \lim _{v \rightarrow \bar{v}} \beta^{\mathrm{E}}(v)=2 \bar{v}-\mathbb{E}(V) .
$$

Therefore, the expected revenue equivalence is restored asymptotically for the second-price and the English auctions when either the winner's payment or her bid is disclosed.

\section{2 | Only winner's identity revealed}

We now compare our results with the information setting in which only the winner's identity is disclosed to the receiver. Without information about either the payment or the bids, the receiver uses the information about who is the winner to update his beliefs about the different bidders. We denote $\beta^{\mathrm{II}, \mathrm{Id}}$ corresponding bidding function in the secondprice auction.

In the second-price auction upon seeing who is the winner, the expectation of the winner's type is the expectation that her type is higher than all the losers' type, $\int_{\underline{v}}^{\bar{v}} \mathbb{E}(V \mid V \geq y) d F^{n-1}(y)$. The receiver cannot distinguish between the $n-1$ losers, and so his expectation of a loser's type is the expectation that her type is below than winner's type, $\int_{\underline{v}}^{\bar{v}} \mathbb{E}(V \mid V \leq y) d F^{n-1}(y)$. As the winning and losing expected inferences are both constant, the bidding equilibrium is inflated by the difference of these two numbers. Giovannoni and Makris (2014) analyzed the second-price auction and determined that the fully separating equilibrium is given by

$$
\beta^{\mathrm{II}, \mathrm{Id}}(v)=v+\int_{\underline{\underline{v}}}^{\bar{v}} \mathbb{E}(V \mid V \geq y) d F^{n-1}(y)-\int_{\underline{v}}^{\bar{v}} \mathbb{E}(V \mid V \leq y) d F^{n-1}(y) .
$$

The information available for the receiver when only the winner's identity is revealed is constant and the same in the second-price and the English auctions. Then, if a fully separating equilibrium exists in the English auction, both auctions lead to the same expected revenue, as is Section 6.1. We denote $\mathrm{ER}^{\mathrm{Id}}$ the expected revenue when the winner's bid is revealed.

The difference of expected revenue reflects again the difference of amount of available information to the receiver and the bidders, and plays in favor of revealing only the winner's identity in the second-price auction (if $f^{\prime}(\cdot) \leq 0$, condition on equilibrium existence). We state this result in the following proposition:

Proposition 5 (Winner's identity and her payment vs. winner's identity). Assume the conditions for the existence of a fully separating equilibrium are satisfied. If $n \geq 4$, then in the D1 PBE

$$
\mathrm{ER}^{\mathrm{Id}}>\mathrm{ER}^{\mathrm{II}}>\mathrm{ER}^{\mathrm{E}}
$$

When only the winner's identity is revealed, the receiver's expected inference between winning and losing is the same for every bidder's type. That contrasts with the second-price auction when the winner's payment is revealed, which creates higher incentives for low bidders types. This result highlights that disclosing less information is a better choice if the auctioneer has the objective to maximize the revenue. 


\section{3 | All bids and bidders' identities revealed}

Finally we compare our results with the case, in which all bids and corresponding bidders' identities are disclosed to the receiver. We denote $\beta^{\mathrm{II}, \mathrm{A}}$ corresponding bidding function in the second-price auction.

In the second-price auction the bidder's type, $v$, is fully revealed to receiver, as $\beta^{-1}(\beta(v))=v{ }^{19}$ Therefore the receiver's expectation of a loser's valuation as well a winner's valuation is their true valuation. Giovannoni and Makris (2014) analyzed this second-price auction and determined that the fully separating equilibrium is given by

$$
\beta^{\mathrm{II}, \mathrm{A}}(v)=v+\frac{1}{(n-1) f(v) F^{n-2}(v)} .
$$

This equilibrium requires two existence conditions ${ }^{20}$ : (i) (lower bound condition) there exists a positive and finite number $N$ such that $\lim _{v \rightarrow \underline{v}} \frac{1}{\left(F^{n-1}(v)\right)^{\prime}} \leq N$, and (ii) (distribution) $F^{n-1}$ is a concave function.

Remark that as for the other information settings considered in this section, if a fully separating equilibrium exists, the information available for the receiver when all bids and bidders' identities are revealed is the same in the secondprice and the English auctions. Therefore, these two auctions are revenue equivalent. We denote $\mathrm{ER}^{\mathrm{A}}$ the expected revenue when all bids and bidders' identities are revealed.

The following proposition determines that revealing all bids and the bidders' identities yields to a higher expected revenue than revealing only the winner's identity and her payment if either there are a large enough number of bidders or $\underline{v}=0$.

Proposition 6 (Winner's identity and her payment vs. all bids and bidders' identities). Assume the conditions for the existence of a fully separating equilibrium are satisfied. If $n$ is sufficiently large or, if $n \geq 4$ and $\underline{v}=0$, then in the $D 1 P B E$

$$
\mathrm{ER}^{\mathrm{A}}>\mathrm{ER}^{\mathrm{II}}>\mathrm{ER}^{\mathrm{E}}
$$

When all bids are revealed, the receiver can pin down the types of all bidders. Therefore every bidder knows that independently of the auction outcome she will be perceived as the type revealed by her own bid. If the number of bidders is large enough, low and medium types know there is a high probably that another bidder with a higher type participates to the auction (or even with the highest type $\bar{v}$ ). For a sufficiently large number of bidders, that creates higher incentives to overbid than when the winner's identity and her payment are revealed.

Therefore if the auctioneer can decide and there are a large number of potential bidders, he will disclose all bids and rather than only the winner's payment. That requires that the existence conditions for the equilibrium are satisfied. Yet for common knowledge distributions, such as the uniform distribution, the fully separating equilibrium in the second-price auction when all bids are disclosed does not exist. That makes the use of the second-price auction, in which either only the winner's identity or the winner's identity and her payment are revealed more relevant for many environments.

\section{7 | CONCLUDING REMARKS}

We have studied the second-price and the English "button" auctions with signaling, assuming that all bidders care about an outside observer's beliefs about their type, if the outside observer sees the identity and payment of the auction's winner. We show that if the outside party's beliefs satisfy a common refinement criterion (D1) and if the type distribution function is concave, then any equilibrium bidding function must be fully separating. Moreover, we obtain a strict expected revenue ranking of the second-price and the English auction formats for a finite number of bidders: the second-price auction strictly outperforms the English auction. Revenue equivalence is only restored asymptotically, if the number of bidders goes to infinity.

These differences in expected revenue stem from the differences in information available to bidders in both auction formats. On the one hand, in both designs, the winner does not pay her own bid, such that the winner's payment only imposes a lower bound on the receiver's expected beliefs about the winner's type. This incites the lowest valuation types 
to bid considerably above their valuation, thus boosting the expected revenue in both auctions. The reason is that if they win the auction, they pay the bid of an even lower type, while the receiver's expected inference about the winner is just above the ex ante average valuation and the expected inference about the losers is close to the lowest possible valuation. On the other hand, the increasing price clock in the English auction constrains the set of potential second-highest bidders at each moment. If the auction has no winner at a certain price, then the second-highest bidder in the auction is at least willing to pay this price. In the sealed-bid auctions, such a constraint is absent and a bidder can only depend on her own bid to constrain the expected inference of the receiver about her in the case of her losing the auction. This additional return to bidding in sealed-bid auctions explains the superiority of the second-price auction over the English auction.

Remark that we kept constant the revealed information to the outside observer, which is the identity of the winner and her payment, in both auction formats. This is a relevant assumption which makes the auctions comparison consistent. However, we should keep in mind that in many English auctions in practice additional information is disclosed to the outside observer. For example, in art and charity auctions all bids are observable by the outsider. This additional released information explains very probably the prevalence of the English auction in practice.

We also compared our results with other information disclosures relevant in practice, to provide a better understanding of how revealing information is crucial for the bidders' strategic behavior. We showed that the use of the second-price auction when only the winner's identity is revealed leads to a higher revenue than to also reveal the winner's payment. However revealing the winner's bid instead of her payment yields to a lower revenue because of the too low additional incentives it creates for low bidders' type. Finally, if revealing all bids and bidders' identities lead to the highest expected revenue for the second-price auction with a sufficiently large number of bidders, this requires some conditions on the equilibrium existence which is not fulfilled by some common distributions.

\section{1 | Dynamic features}

In short, we show that dynamic features of the auction format affect the expected revenue if bidders care about a receiver's inferences about their type. This disaccords with Goeree's (2003) finding of revenue equivalence in the presence of signaling incentives. This difference originates from three crucial differences between Goeree's setting and the present model. First, Goeree assumes that the uninformed party observes the winner's bid, rather than her payment. In the second-price auction, this implies a full revelation of the winner's type in Goeree's setting. In the present setting, the incomplete revelation of the winner's type causes the low types to bid significantly above their valuation in the second-price auction. Second, higher bidder types care strictly more about the receiver's inferences in Goeree's setting, and this single crossing condition allows winning bidders to fully reveal their type in the English auction. This equally constrains the equilibrium bids of the lowest types in comparison to the present setting. Third, unlike in Goeree (2003), losing bidders also care about the receiver's inferences in the present setting, and this increases in particular the equilibrium bidding the sealed-bid auctions.

\section{2 | Robustness of our results for nonlinear signaling concerns}

A natural follow-up question is to determine if the above-expected revenue ranking strongly relies on the linearity of the bidders' payoff function w.r.t. the receiver's beliefs. An exhaustive analysis, establishing existence and uniqueness of the fully separating equilibrium, is left for future research. We focus on a simple exploration of a payoff function that is nonlinear w.r.t. the receiver's beliefs. Consider a strictly increasing function $\Phi:[\underline{v}, \bar{v}] \rightarrow \mathbb{R}_{+}$, measuring the payoffs that bidders draw from the perception of their type by the receiver. ${ }^{21}$ The bidder's payoff function is then given by

$$
u_{i}\left(v_{i}, p_{i} \mid \mu_{i}\right)= \begin{cases}v_{i}-p_{i}+\Phi\left(\mathbb{E}\left(V_{i} \mid \mu_{i}\left(V_{i} \mid i^{\star}, p_{i^{\star}}\right)\right)\right) & \text { for winner } i=i^{\star}, \\ \Phi\left(\mathbb{E}\left(V_{i} \mid \mu_{i}\left(V_{i} \mid i^{\star}, p_{i^{\star}}\right)\right)\right) & \text { for loser } i \neq i^{\star},\end{cases}
$$

To simplify the exposition we denote $K(v):=\frac{1}{1-F(v)} \int_{v}^{\bar{v}} x d F(x)$ and $G(v):=\frac{v}{n-1}+\frac{n-2}{n-1} \frac{\int_{\underline{v}}^{v} x d F(x)}{F(v)}$. 
In the second-price auction, the expected utility of a valuation $v$ bidder choosing type- $\tilde{v}^{\prime} \mathrm{s}$ bidding strategy becomes then

$$
\begin{aligned}
& \int_{\underline{v}}^{\tilde{v}}\left(v-\beta^{\mathrm{II}}(x)\right) d F^{n-1}(x)+\int_{\underline{v}}^{\tilde{v}} \Phi(K(x)) d F^{n-1}(x)+(n-1) F^{n-2}(\tilde{v})(1-F(\tilde{v})) \Phi(G(\tilde{v})) \\
& \quad+\int_{\tilde{v}}^{\bar{v}} \Phi(G(y)) d\left((n-1) F^{n-2}(y)-(n-2) F^{n-1}(y)\right) .
\end{aligned}
$$

The first-order condition is

$$
\begin{aligned}
\beta^{\mathrm{II}}(\tilde{v})\left(F^{n-1}(\tilde{v})\right)^{\prime}= & v\left(F^{n-1}(\tilde{v})\right)^{\prime}+\Phi(K(\tilde{v}))\left(F^{n-1}(\tilde{v})\right)^{\prime}+(n-1)\left(\left(F^{n-2}(\tilde{v})\right)^{\prime}-\left(F^{n-1}(\tilde{v})\right)^{\prime}\right) \Phi(G(\tilde{v})) \\
& +(n-1) F^{n-2}(\tilde{v})(1-F(\tilde{v})) \Phi^{\prime}(G(\tilde{v})) G^{\prime}(\tilde{v}) \\
& -\Phi(G(\tilde{v}))\left((n-1)\left(F^{n-2}(\tilde{v})\right)^{\prime}-(n-2)\left(F^{n-1}(\tilde{v})\right)^{\prime}\right) .
\end{aligned}
$$

After dividing both sides by $\left(F^{n-1}(\tilde{v})\right)^{\prime}=(n-1) F^{n-2}(\tilde{v}) f(\tilde{v})$, imposing $\tilde{v}=v$ and simplifying, we obtain

$$
\beta^{\mathrm{II}}(v)=v+\Phi(K(v))+\frac{(n-1)(1-F(v))}{(n-2) f(v)} \Phi^{\prime}(G(v)) G^{\prime}(v)-\Phi(G(v)) .
$$

In the English auction, the exit rule equation (3) to determines the auction price becomes

$$
v-\beta^{\mathrm{E}}(\tilde{v})+\Phi(K(\tilde{v}))=\Phi(G(\tilde{v})) .
$$

Imposing $\tilde{v}=v$ it follows

$$
\beta^{\mathrm{E}}(v)=v+\Phi(K(v))-\Phi(G(v)) .
$$

A comparison of the bidding functions shows that for every strictly increasing function $\Phi$, the second-price auction outperforms the English auction in terms of expected revenue.

\section{3 | Entry fees}

The assumption that losing bidders equally care about the receiver's inferences reflects a situation in which the receiver is interested in bidders' valuations as a reflection of individual characteristics, such that the auction's outcome is informative about these characteristics, irrespective of whether a bidder won or lost. If participation is exogenously given, then nonparticipating bidders get inference $\mathbb{E}(V)$ in the absence of information transmission, and are in equilibrium generically strictly better off than losing participating bidders. Does that mean that bidders prefer to stay out if entry were endogenous? Not really. If entry were endogenous and if the receiver observes the entry decision of each bidder besides the winner's identity and payment, then the participation decision becomes informative. Consider then a cutoff type $\hat{v}$, with $\hat{v}<\bar{v}$, such that higher valuation types participate, while lower types stay out. If the $\hat{v}$-type bidder stays out, she gets $\mathbb{E}(V \mid V \leq \hat{v})$. If the cutoff type $\hat{v}$ participates, she wins with probability zero if $\beta^{\prime}(\cdot)>0$, and gets a receiver's inference between $\hat{v}$ and the winner's valuation. Hence, the cutoff type $\hat{v}$ is strictly better off participating, and endogenous participation implies full participation. Moreover, this means that the auctioneer can and should ask for a strictly positive entry fee. The auctioneer can guarantee full participation while asking all bidders to pay an entry fee which makes the type- $\underline{v}$ bidder indifferent between participation and nonparticipation (and payoff $\underline{v}$ ). Unfortunately, a characterization of the optimal entry fee is in this setting, not a trivial exercise, and is as such outside the scope of this paper. Bos and Truys (2019) provide a reply for the first-price auction while Bos and Pollrich (2020) determine optimal entry fees through a mechanism design approach. 


\section{ACKNOWLEDGMENTS}

We are grateful for helpful comments and suggestions by an anonymous co-editor and two anonymous referees. We would like to thank Claude d'Aspremont, Francis Bloch, Damian Damianov, David Ettinger, Françoise Forges, Francesco Giovannoni, Frédéric Koessler, Laurent Lamy, Miltiadis Makris, Michel Le Breton, Sander Onderstal, Alessandro Pavan, Martin Pollrich, Régis Renault, and Jean-Marc Tallon for comments and/or helpful discussions. We also thank participants in various seminars and workshops, including Aarhus University, ENSAI, Maastricht University, Paris Game Theory Seminar, Saint-Louis University-Brussels, Université Catholique de Louvain, University of St. Gallen, UECE Lisbon Meetings in Game Theory, Hurwicz Workshop on Mechanism Design Theory 2018, and International Conference on Game Theory-Stony Brook. Olivier Bos gratefully acknowledges financial support from the ANR DBCPG grant. This study has been conducted as part of the project Labex MME-DII (ANR11-LBX-0023-01). Tom Truyts gratefully acknowledges financial support from the ARC project no. 15/20-072, "Social and Economic Network Formation under Limited Farsightedness: Theory and Applications." Open access funding enabled and organized by Projekt DEAL.

\section{ENDNOTES}

${ }^{1}$ See Frank $(1985,1999)$ for a broad introduction to social status in economics, Miller (2000) for an introduction to the biological roots of status concerns, Mason (1998) for a history of economic thought w.r.t. status concerns, and Truyts (2010) for a recent survey of the literature. See also Riley (2001) for more specific applications of signaling theory in this context. Cole et al. (1992) derive preferences for status from a two-sided one-to-one matching problem. If the equilibrium matching is assortative, one must appear more attractive than one's peers to secure the best attainable partner. See also Cole and Postlewaite (2001) and Postlewaite (1998).

${ }^{2}$ See, for example, Engers and McManus (2007) and Goeree et al. (2005).

${ }^{3}$ Glazer and Konrad (1996) and Harbaugh (1998a, 1998b) show that signaling is an important explanation for observed patterns in donations to universities. Kumru and Vesterlund (2010) find that donations are significantly higher if the charity first collects from high-status sponsors because donators like to be associated with higher status groups.

${ }^{4}$ Note that, in general, a bidder's private valuation can reflect, for example, purchasing power, a taste for art, generosity, profitability prospects, expected market penetration, or a combination of such factors. To keep the model as simple and generic as possible, we disregard how these qualities map into a private valuation, and how the receiver seeks to reverse this mapping to form beliefs about these ultimate qualities from the auction outcome.

${ }^{5}$ Auctions with different disclosure policies are also studied in, for example, Lebrun (2010), Fan et al. (2016), Bergemann and Hörner (2018), and Azacis (2020).

${ }^{6}$ We denote the bidding strategy in any auction format by $\beta$, and only add an additional superscript to specify the auction format when comparing bidding functions of different auction formats for an expected revenue comparison.

${ }^{7}$ That is, for all $i \in\left\{j \mid b_{j}=\max \boldsymbol{b}\right\}$ we have $\operatorname{Pr}\left(i=i^{\star}\right)=\frac{1}{\left|\left\{j \mid b_{j}=\max \boldsymbol{b}\right\}\right|}$.

${ }^{8}$ https://www.beaune-tourism.com/discover/hospices-de-beaune-wine-auction.

${ }^{9}$ See Annex V part D of Directive 2014/24/EU of the European Parliament and of the Council of February 26, 2014 on public procurement: https://eur-lex.europa.eu/legal-content/EN/TXT/PDF/?uri=CELEX:02014L0024-20200101\&from=EN (last accessed July 8, 2020).

${ }^{10}$ Note that then $\mu_{i}\left(v \mid\left(i^{\star}, p_{i^{\star}}\right)\right)=\int_{\left\{\boldsymbol{v} \mid v_{i}=v\right\}} \mu\left(\boldsymbol{v} \mid\left(i^{\star}, p_{i^{\star}}\right)\right) d \boldsymbol{v}$.

${ }^{11}$ It can strike readers as counterintuitive that losing bidders seem to win something in terms of the receiver's inference. However, this is only true if nonparticipants receive payoff zero. Rather, we assume that the receiver always forms beliefs about the bidders. Under exogenous participation, a nonparticipating bidder obtains payoff $\mathbb{E}(V)$, because the auction reveals no information about her. In this case, losing bidders lose in equilibrium compared with their nonparticipation payoff. We return to this issue in Section 7, where we discuss endogenous entry.

${ }^{12}$ Note that Goeree (2003) can allow for a more general implicit payoff function. However, the receiver's equilibrium beliefs are necessarily degenerate in his setting. In the present setting with nondegenerate equilibrium beliefs, such payoff functions entail far more complications and a loss of some tractable solutions and results. Moreover, the main intuitions are more clearly presented with a linear structure. One can also conceive a payoff function

$$
\begin{cases}v_{i}-p_{i}+\gamma \mathbb{E}\left(V_{i} \mid \mu_{i}\left(V_{i} \mid i^{\star}, p_{i^{\star}}\right)\right) & \text { for winner } i=i^{\star}, \\ \gamma \mathbb{E}\left(V_{i} \mid \mu_{i}\left(V_{i} \mid i^{\star}, p_{i^{\star}}\right)\right) & \text { for loser } i \neq i^{\star},\end{cases}
$$

with $0<\gamma<\infty$ measuring the relative importance of signaling. This would not change our results qualitatively, but merely complicate the analysis. Examples 1 and 2 present an analysis with such a scalar $\gamma$ to provide a better understanding on how the relative importance of signaling concerns in the bidders' payoff function affects the bidding behavior. The robustness of the revenue comparison is also discussed in Section 7 , for a payoff function that is nonlinear w.r.t. the receiver's inference. 
${ }^{13}$ As outlined in Appendix A, the exact formal implementation of the D1 criterion depends on the auction format. Formally, for types $v^{\prime}, v^{\prime \prime}$ and out-of-equilibrium message $m$, beliefs $\mu$, a utility function $u(m, \mu \mid v)$, and equilibrium utility levels $u^{\star}(v)$ define the following two sets of beliefs which make a type $v$ sending $m$, respectively, strictly better off than in equilibrium and equally well off as in equilibrium:

$$
\begin{aligned}
& \mathcal{M}^{+}(m, v)=\left\{\mu \mid u(m, \mu \mid v)>u^{\star}(v)\right\}, \\
& \mathcal{M}^{0}(m, v)=\left\{\mu \mid u(m, \mu \mid v)=u^{\star}(v)\right\} .
\end{aligned}
$$

Then the D1 criterion requires

$$
\mathcal{M}^{+}\left(m, v^{\prime}\right) \cup \mathcal{M}^{0}\left(m, v^{\prime}\right) \subset \mathcal{M}^{+}\left(m, v^{\prime \prime}\right) \Rightarrow \mu\left(v^{\prime} \mid m\right)=0
$$

${ }^{14}$ Clearly, Goeree's (2003) condition allows for a broader class of type distributions. However, Goeree (2003) ensures the existence of a fully separating equilibrium by imposing that the winning bidder's payoffs are strictly convex w.r.t. the uninformed party's inference. In the present setting with linear payoffs, this is achieved by a stronger restriction on the type distribution.

${ }^{15}$ We use 'fully separating' to indicate that no bid is chosen by different types in equilibrium. In the present setting, this does not imply that the receiver's equilibrium beliefs are degenerate, which is sometimes used as an alternative definition of 'fully separating' equilibrium.

${ }^{16}$ Obviously other information regimes, for example, the receiver observing all bids, are equally plausible in this setting. The plausibility of these different scenarios depends on the specific context and the identity of the receiver (e.g., another bidder or the general public reading media outlets). For example, the English auction formats used in practice for art and charity are usually reveal more information to the receiver (e.g., all bids). This likely leads to a different ranking of revenues. This issue is discussed in Section 7.

${ }^{17} \mathrm{We}$ omit only here the superscript II, B for a better readability.

${ }^{18}$ See Giovannoni and Makris' Proposition 5.

${ }^{19}$ We omit only here the superscript II, A for a better readability.

${ }^{20}$ See Assumption 2 and Proposition 5 in Giovannoni and Makris (2014).

${ }^{21}$ This assumption implies that the marginal payoff from signaling increases with the receiver's inference, for example, because the stakes for higher types are higher in an aftermarket. See, for example, Molnar and Virag (2008).

\section{ORCID}

Olivier Bos (D) http://orcid.org/0000-0003-3148-4207

\section{REFERENCES}

Avery, C. (1998). Strategic jump bidding in English auctions. The Review of Economic Studies, 65(2), 185-210.

Azacis, H. (2020). Information disclosure by a seller in a sequential first-price auction. International Journal of Game Theory, 49, 411-444. Banks, J. S., \& Sobel, J. (1987). Equilibrium selection in signaling games. Econometrica, 55, 647-661.

Bergemann, D., \& Hörner, J. (2018). Should first-price auctions be transparent? American Economic Journal: Microeconomics, 10(3), 177-218. Bos, O., \& Pollrich, M. (2020). Optimal auctions with signaling bidders. Mimeo.

Bos, O., \& Truys, T. (2019). Entry in first-price auctions with signaling. Mimeo.

Carpenter, J., Homes, J., \& Matthews, P. H. (2008). Charity auctions: A field experiment. Economic Journal, 118, 92-113.

Cole, H. L., Malaith, G. J., \& Postlewaite, A. (1992). Social norms, savings behavior, and growth. Journal of Political Economy, 100, 1092-1125.

Cole, H. L., Mailath, G. J., \& Postlewaite, A. (2001). Investment and concern for relative position. Review of Economic Design, 6, $241-261$.

Das Varma, G. (2003). Bidding for a process innovation under alternative modes of competition. International Journal of Industrial Organization, 21(1), 15-37.

Dworczak, P. (2020). Mechanism design with aftermarkets: Cutoff mechanisms. Econometrica (forthcoming).

Engers, M., \& McManus, B. (2007). Charity auction. International Economic Review, 48(3), 953-994.

Fan, C., Jun, B. H., \& Wolfstetter, E. G. (2016). Optimal bid disclosure in patent license auctions under alternative modes of competition. International Journal of Industrial Organization, 47, 1-32.

Frank, R. (1985). Choosing the right pond: Human behavior and the quest for status. Oxford University Press.

Frank, R. (1999). Luxury fever: Money and happiness in an era of excess. Princeton University Press.

Giovannoni, F., \& Makris, M. (2014). Reputational bidding. International Economic Review, 55(3), 693-710.

Glazer, A., \& Konrad, K. (1996). A signalling explanation for charity. American Economic Review, 86, $1019-1028$.

Goeree, J. K. (2003). Bidding for the future: Signaling in auctions with an aftermarket. Journal of Economic Theory, 108(2), 345-364.

Goeree, J. K., Maasland, E., Onderstal, S., \& Turner, J. L. (2005). How (not) to raise money. Journal of Political Economy, 113(4), 897-918. Haile, P. (2003). Auctions with private uncertainty and resale opportunities. Journal of Economic Theory, 108(1), 72-110.

Harbaugh, W. T. (1998a). The prestige motive for making charitable transfers. American Economic Review, 88, $277-282$. 
Harbaugh, W. T. (1998b). What do donations buy? A model of philanthropy based on prestige and warm glow. Journal of Public Economics, 67, 260-284.

Hörner, J., \& Sahuguet, N. (2007). Costly signalling in auctions. The Review of Economic Studies, 74(1), 173-206.

Katzman, B. E., \& Rhodes-Kropf, M. (2008). The consequences of information revealed in auctions. Applied Economics Research Bulletin, 2, 53-87.

Kumru, C., \& Vesterlund, L. (2010). The effect of status on charitable giving. Journal of Public Economic Theory, 12(4), 709-735.

Lebrun, B. (2010). First-price auctions with resale and with outcomes robust to bid disclosure. The RAND Journal of Economics, 41, $165-178$.

Liu, T. (2012). Takeover bidding with signaling incentives. Review of Financial Studies, 25(2), 522-556.

Mandel, B. R. (2009). Art as an investment and conspicuous consumption good. American Economic Review, 99(4), 1653-1663.

Mason, R. (1998). The economics of conspicuous consumption: Theory and thought since 1700. Edward Elgar.

Mei, J., \& Moses, M. (2002). Art as an investment and the underperformance of masterpieces. American Economic Review, 92(5), $1656-1668$.

Milgrom, P. (2004). Putting auction to work. Cambridge University Press.

Milgrom, P., \& Weber, R. (1982). A theory of auctions and competitive bidding. Econometrica, 50, 1089-122.

Miller, G. (2000). The mating mind: How sexual choice shaped the evolution of human nature. Anchor Books.

Molnar, J., \& Virag, G. (2008). Revenue maximizing auctions with market interaction and signaling. Economics Letters, 99(2), 360-363.

Postlewaite, A. (1998). The social basis of interdependent preferences. European Economic Review, 42, 779-800.

Rayo, L. (2013). Monopolistic signal provision. The BE Journal of Theoretical Economics, 13(1), 27-58.

Riley, J. G. (2001). Silver signals: Twenty-five years of screening and signaling. Journal of Economic Literature, 39, 432-478.

Truyts, T. (2010). Social status in economic theory. Journal of Economic Surveys, 24(1), 137-169.

How to cite this article: Bos O, Truyts T. Auctions with signaling concerns. J Econ Manage Strat. 2021;30: 420-448. https://doi.org/10.1111/jems.12406

\section{APPENDIX A}

\section{Proof of Lemma 1}

The proof proceeds in three steps: (1) establish for any D1 PBE the bidding function $\beta$ is weakly increasing, (2) show in any D1 PBE, there is no pooling with the $\underline{v}$ type, and (3) show in any D1 PBE, there is no pooling above the $\underline{v}$ type.

Let $\operatorname{Pr}(1 \mid b), \operatorname{Pr}(2 \mid b)$, and $\operatorname{Pr}(3 \mid b)=1-\operatorname{Pr}(1 \mid b)-\operatorname{Pr}(2 \mid b)$, respectively, denote the probabilities of winning, having the second-highest bid and having a lower bid with bid $b$, and let $E^{1}(b), E^{2}(b)$, and $E^{l}(b)$ be the expected inferences of the receiver if a bidder with bid $b$, respectively, wins, has the second-highest bid and loses, and let $E^{p}(b)$ be the expected payment of a winner with bid $b$.

Claim A1 ( $\beta$ weakly increasing). If a $v^{\prime}$ type bids $b^{\prime}$ in equilibrium, then no $v^{\prime \prime}<v^{\prime}$ bids $b^{\prime \prime}>b^{\prime}$ in equilibrium.

Proof. Assume the opposite. Because both $b^{\prime}$ and $b^{\prime \prime}$ are sent in equilibrium, it must be that $\operatorname{Pr}\left(1 \mid b^{\prime \prime}\right)>\operatorname{Pr}\left(1 \mid b^{\prime}\right)$. Then if $v^{\prime \prime}$ bids $b^{\prime \prime}$ in equilibrium, it must be that

$$
\begin{aligned}
& \operatorname{Pr}\left(1 \mid b^{\prime \prime}\right)\left(v^{\prime \prime}-E^{p}\left(b^{\prime \prime}\right)+E^{1}\left(b^{\prime \prime}\right)\right)+\operatorname{Pr}\left(2 \mid b^{\prime \prime}\right) E^{2}\left(b^{\prime \prime}\right) \\
& \quad+\left(1-\operatorname{Pr}\left(1 \mid b^{\prime \prime}\right)-\operatorname{Pr}\left(2 \mid b^{\prime \prime}\right)\right) E^{l}\left(b^{\prime \prime}\right) \\
& \quad \geq \operatorname{Pr}\left(1 \mid b^{\prime}\right)\left(v^{\prime \prime}-E^{p}\left(b^{\prime}\right)+E^{1}\left(b^{\prime}\right)\right) \\
& \quad+\operatorname{Pr}\left(2 \mid b^{\prime}\right) E^{2}\left(b^{\prime}\right)+\left(1-\operatorname{Pr}\left(1 \mid b^{\prime}\right)-\operatorname{Pr}\left(2 \mid b^{\prime}\right)\right) E^{l}\left(b^{\prime}\right) .
\end{aligned}
$$

But given that $\operatorname{Pr}\left(1 \mid b^{\prime \prime}\right)>\operatorname{Pr}\left(1 \mid b^{\prime}\right)$, this implies that the $v^{\prime}$ type strictly prefers a $b^{\prime \prime}$ bid above $b^{\prime}$, which contradicts the equilibrium. Assume then that in equilibrium the $v^{\prime \prime}$-type's equilibrium expected utility is so low that $\mathcal{M}^{+}\left(b^{\prime \prime}, v^{\prime}\right) \subseteq \mathcal{M}^{+}\left(b^{\prime \prime}, v^{\prime \prime}\right) \cup \mathcal{M}^{0}\left(b^{\prime \prime}, v^{\prime \prime}\right)$, then it must be that the $v^{\prime \prime}$ strictly prefers the bundle $\left(b^{\prime}, E^{1}\left(b^{\prime}\right), E^{2}\left(b^{\prime}\right), E^{l}\left(b^{\prime}\right), E^{p}\left(b^{\prime}\right)\right)$ to her equilibrium strategy, a contradiction. Hence, if type $v^{\prime}$ bids $b^{\prime}$ in equilibrium, then $\mu\left(v^{\prime \prime} \mid b^{\prime \prime}\right)=0$, and no $v^{\prime \prime}$ type with $v^{\prime \prime}<v^{\prime}$ chooses a $b^{\prime \prime}$ bid, with $b^{\prime \prime}>b^{\prime}$. 
Claim A2 (No pooling with $\underline{v}$ ). In the D1 PBE, no other type pools with $\underline{v}$.

Proof. Suppose a nondegenerate set of types $\mathcal{O}=\{v \mid \beta(v)=\tilde{b}\}$, with $\underline{v} \in \mathcal{O}$, pool in equilibrium at bid $\tilde{b}$. If $n \geq 3$, then if type $\underline{v}$ (or a type just above her) deviates to a bid $\tilde{b}-\varepsilon$, for $\varepsilon>0$, she has zero probability of having the highest or second-highest bid, while the expected inference if she loses remains unchanged at $E^{l}(\tilde{b})$. In equilibrium, such a deviation cannot be profitable such that

$$
\operatorname{Pr}(1 \mid \tilde{b})\left(\underline{v}-\tilde{b}+E^{1}(\tilde{b})\right)+\operatorname{Pr}(2 \mid \tilde{b}) E^{2}(\tilde{b})+(1-\operatorname{Pr}(1 \mid \tilde{b})-\operatorname{Pr}(2 \mid \tilde{b})) E^{l}(\tilde{b}) \geq E^{l}(\tilde{b})
$$

or that

$$
\frac{\operatorname{Pr}(1 \mid \tilde{b})}{\operatorname{Pr}(1 \mid \tilde{b})+\operatorname{Pr}(2 \mid \tilde{b})}\left(\underline{v}-\tilde{b}+E^{1}(\tilde{b})\right)+\frac{\operatorname{Pr}(2 \mid \tilde{b})}{\operatorname{Pr}(1 \mid \tilde{b})+\operatorname{Pr}(2 \mid \tilde{b})} E^{2}(\tilde{b}) \geq E^{l}(\tilde{b}) .
$$

Note that because $E^{2}(\tilde{b}) \leq E^{l}(\tilde{b})$, it must be that

$$
\underline{v}-\tilde{b}+E^{1}(\tilde{b}) \geq E^{2}(\tilde{b}) .
$$

If the $\sup (\mathcal{O})$ type would deviate to a bid $\tilde{b}+\varepsilon$, for $\varepsilon>0$ small enough such that $\tilde{b}+\varepsilon$ is out-of-equilibrium and no equilibrium bids are in $(\tilde{b}, \tilde{b}+\varepsilon)$, she still pays $\tilde{b}$ and gets expected inference $E^{1}(\tilde{b})$ if winning, is inferred as $E^{2}(\tilde{b}+\varepsilon)>E^{2}(\tilde{b})$ if having the second-highest bid and has expected inference $E^{l}(\tilde{b}+\varepsilon)$ if losing. For $\sup (\mathcal{O})$ to bid $\tilde{b}$ in equilibrium, it must be that

$$
\begin{aligned}
& \operatorname{Pr}(1 \mid \tilde{b}+\varepsilon)\left(\sup (\mathcal{O})-\tilde{b}+E^{1}(\tilde{b})\right) \\
& \quad+\operatorname{Pr}(2 \mid \tilde{b}+\varepsilon) E^{2}(\tilde{b}+\varepsilon)+(1-\operatorname{Pr}(1 \mid \tilde{b}+\varepsilon)-\operatorname{Pr}(2 \mid \tilde{b}+\varepsilon)) E^{l}(\tilde{b}+\varepsilon) \\
& \quad \leq \operatorname{Pr}(1 \mid \tilde{b})\left(\sup (\mathcal{O})-\tilde{b}+E^{1}(\tilde{b})\right)+\operatorname{Pr}(2 \mid \tilde{b}) E^{2}(\tilde{b})+\operatorname{Pr}(3 \mid \tilde{b}) E^{l}(\tilde{b}) .
\end{aligned}
$$

Note then that

$$
E^{l}(\tilde{b})=\frac{\operatorname{Pr}(3 \mid \tilde{b}+\varepsilon)}{\operatorname{Pr}(3 \mid \tilde{b})} E^{l}(\tilde{b}+\varepsilon)+\frac{\operatorname{Pr}(3 \mid \tilde{b})-\operatorname{Pr}(3 \mid \tilde{b}+\varepsilon)}{\operatorname{Pr}(3 \mid \tilde{b})} E^{2}(\tilde{b})
$$

that is, if the $\sup (\mathcal{O})$ type is neither winning nor second when pooling at $\tilde{b}$, then the second-highest bidder either has a higher valuation or she is in $\mathcal{O}$. In the former case, the receiver's expected inference is $E^{l}(\tilde{b}+\varepsilon)$. In the latter case it must be $E^{2}(\tilde{b})$. Substituting (A3) this in (A2), we obtain

$$
\begin{aligned}
& (\operatorname{Pr}(1 \mid \tilde{b}+\varepsilon)-\operatorname{Pr}(1 \mid \tilde{b}))\left(\sup (\mathcal{O})-\tilde{b}+E^{1}(\tilde{b})-E^{2}(\tilde{b})\right) \\
& \quad+\operatorname{Pr}(2 \mid \tilde{b}+\varepsilon)\left(E^{2}(\tilde{b}+\varepsilon)-E^{2}(\tilde{b})\right) \leq 0
\end{aligned}
$$

which can only be satisfied is $\sup (\mathcal{O})=\underline{v}$.

Claim A3 (No pooling above $\underline{v}$ ). In the D1 PBE there is no pooling at bids strictly above $\underline{v}$.

Proof. To save on notation let $p(b)$, instead of $\operatorname{Pr}(1 \mid b)$, denote the probability of winning the auction with bid $b$. Assume that $\tilde{b}$ is the lowest bid at which a nondegenerate set of types $\mathcal{O}=\{v \mid \beta(v)=\tilde{b}\}$ pool. The same envelope theorem argument as for the first-price auction also works for the second. Note then again that the expected utility difference between $\sup (\mathcal{O})$ and $\inf (\mathcal{O})$ while pooling at $\tilde{b}$ is $p(\tilde{b})(\sup (\mathcal{O})-\inf (\mathcal{O}))$, while in separation this is by the envelope theorem

$$
\int_{\inf (\mathcal{O})}^{\sup (\mathcal{O})} F^{n-1}(x) d x=\sup (\mathcal{O}) F^{n-1}(\sup (\mathcal{O}))-\inf (\mathcal{O}) F^{n-1}(\inf (\mathcal{O}))-\int_{\inf (\mathcal{O})}^{\sup (\mathcal{O})} x d F^{n-1}(x)
$$


We now show that, if $f^{\prime}(\cdot) \leq 0$,

$$
p(\bar{b})(\sup (\mathcal{O})-\inf (\mathcal{O}))<\int_{\inf (\mathcal{O})}^{\sup (\mathcal{O})} F^{n-1}(x) d x .
$$

First write the probability of winning the auction while bidding $\tilde{b}$

$$
p(\tilde{b})=\sum_{i=0}^{n-1}\left(\begin{array}{c}
n-1 \\
i
\end{array}\right) \frac{F^{n-1-i}(\inf (\mathcal{O}))(F(\sup (\mathcal{O}))-F(\inf (\mathcal{O})))^{i}}{i+1} .
$$

Note then that $p(\bar{b})(\sup (\mathcal{O})-\inf (\mathcal{O}))=\int_{\inf (\mathcal{O})}^{\sup (\mathcal{O})} F^{n-1}(x) d x=0$ for $\sup (\mathcal{O})=\inf (\mathcal{O})$. Differentiate both sides of (A4) to $\sup (\mathcal{O})$, to obtain

$$
\frac{\partial p(\bar{b})}{\partial \sup (\mathcal{O})}(\sup (\mathcal{O})-\inf (\mathcal{O}))+p(\bar{b})<F^{n-1}(\sup (\mathcal{O}))
$$

which can be written as

$$
\alpha\left[F^{n-1}(\sup (\mathcal{O}))-p(\bar{b})-F^{n-1}(\inf (\mathcal{O}))\right]<F^{n-1}(\sup (\mathcal{O}))-p(\bar{b}),
$$

with

$$
\alpha=\frac{f(\sup (\mathcal{O}))}{\frac{F(\sup (\mathcal{O}))-F(\inf (\mathcal{O}))}{\sup (\mathcal{O})-\inf (\mathcal{O})}}
$$

because

$$
\begin{aligned}
\frac{\partial p(\bar{b})}{\partial \sup (\mathcal{O})} & =\sum_{i=1}^{n-1}\left(\begin{array}{c}
n-1 \\
i
\end{array}\right) F^{n-1-i}(\inf (\mathcal{O}))(F(\sup (\mathcal{O}))-F(\inf (\mathcal{O})))^{i-1} \frac{i}{i+1} f(\sup (\mathcal{O})) \\
& =\left[F^{n-1}(\sup (\mathcal{O}))-p(\bar{b})-F^{n-1}(\inf (\mathcal{O}))\right] \frac{f(\sup (\mathcal{O}))}{(F(\sup (\mathcal{O}))-F(\inf (\mathcal{O})))},
\end{aligned}
$$

in which the last equality uses

$$
1-p(\bar{b})=\left(1-F^{n-1}(\sup (\mathcal{O}))\right)+\sum_{i=0}^{n-1}\left(\begin{array}{c}
n-1 \\
i
\end{array}\right) F^{n-1-i}(\inf (\mathcal{O}))(F(\sup (\mathcal{O}))-F(\inf (\mathcal{O})))^{i} \frac{i}{i+1} .
$$

Note then that $f^{\prime}(\cdot) \leq 0$ implies $\alpha \leq 1$, such that (A5) and therefore (A4) are always satisfied for $F(\sup (\mathcal{O}))>F(\inf (\mathcal{O}))$ and $f^{\prime}(\cdot) \leq 0$. Then the $\sup (\mathcal{O})$ type can achieve a strictly higher expected utility if she would deviate to the bid she makes in the fully separating equilibrium because the expected inference after such a deviation is at least the expected inference she gets in the fully separating equilibrium. This excludes any different types pooling in a D1 PBE.

\section{Proof of Proposition 1}

The proof proceeds again in three steps: (1) derive the bidding function, (2) show that the second-order condition is satisfied if the bidding functions is strictly increasing, and (3) show that the proposed bidding function is strictly increasing.

Claim A4 (Bidding function). $\beta$ is as written in Proposition 1. 
Proof. From (2), collect terms to obtain

$$
\begin{aligned}
\beta(v)= & \frac{n-2}{n-1} \frac{1}{F(v)}\left(v-\frac{\int_{\underline{v}}^{v} x d F(x)}{F(v)}\right)+\frac{\int_{v}^{\bar{v}} x d F(x)}{1-F(v)}+\frac{1}{(n-1)} \frac{(1-F(v))}{f(v)} \\
= & \frac{n-2}{n-1} \frac{\int_{\underline{v}}^{v} F(x) d x}{F^{2}(v)}+\frac{1}{(n-1)} \frac{\int_{v}^{\bar{v}} f(x) d x}{f(v)}+\frac{\int_{v}^{\bar{v}} x d F(x)}{1-F(v)},
\end{aligned}
$$

where (A7) is obtained from (A6) by partially integrating the first term.

Then by L'Hôpital's rule, $\lim _{v \rightarrow \underline{v}} \frac{\int_{\underline{v}}^{v} F(x) d x}{F^{2}(v)}=\frac{F(\underline{v})}{2 F(\underline{v}) f(\underline{v})}$, while $\lim _{v \rightarrow \bar{v}} \frac{\int_{v}^{\bar{v}} x d F(x)}{1-F(v)}=\frac{-\bar{v} f(\bar{v})}{-f(\bar{v})}=\bar{v}$, such that

$$
\begin{aligned}
& \lim _{v \rightarrow \underline{v}} \beta(v)=\mathbb{E}(V)+\frac{n}{2(n-1) f(\underline{v})}, \\
& \lim _{v \rightarrow \bar{v}} \beta(v)=\bar{v}+\frac{n-2}{n-1}(\bar{v}-\mathbb{E}(V)) .
\end{aligned}
$$

Claim A5 (Second-order condition). The second-order condition is satisfied iff $\beta^{\prime}(\cdot)>0$.

Proof. We first show that a strictly increasing bidding function implies local strict concavity of the bidder's problem, and then that the equilibrium bid is a global expected utility maximizing choice for each bidder.

First, use the first-order condition (3) to define

$$
\begin{aligned}
G(\tilde{v}, v) \equiv & \left(F^{n-1}(\tilde{v})\right)^{\prime}(v-\beta(\tilde{v}))+\frac{\int_{\tilde{v}}^{\bar{v}} x d F(x)}{1-F(\tilde{v})}\left(F^{n-1}(\tilde{v})\right)^{\prime} \\
& +F^{n-2}(\tilde{v})(1-F(\tilde{v}))\left(1+(n-2) \frac{\tilde{v} f(\tilde{v}) F(\tilde{v})-f(\tilde{v}) \int_{\underline{v}}^{\tilde{v}} x d F(x)}{F^{2}(\tilde{v})}\right) \\
& +\left((n-2) f(\tilde{v}) F^{n-3}(\tilde{v})-(n-1) f(\tilde{v}) F^{n-2}(\tilde{v})\right)\left(\tilde{v}+(n-2) \frac{\int_{\underline{v}}^{\tilde{v}} x d F(x)}{F(\tilde{v})}\right) \\
& -\left((n-2) f(\tilde{v}) F^{n-3}(\tilde{v})-(n-2) f(\tilde{v}) F^{n-2}(\tilde{v})\right)\left(\tilde{v}+(n-2) \frac{\int_{\underline{v}}^{\tilde{v}} x d F(x)}{F(\tilde{v})}\right)=0,
\end{aligned}
$$

which defines $\beta(v)$ for $\tilde{v}=v$. Let us denote $G_{1}\left(x_{1}, x_{2}\right) \equiv \frac{\partial G}{\partial x_{1}}\left(x_{1}, x_{2}\right)$ and $G_{2}\left(x_{1}, x_{2}\right) \equiv \frac{\partial G}{\partial x_{2}}\left(x_{1}, x_{2}\right)$. By the implicit function theorem $\beta^{\prime}(v)>0$ if and only if strictly higher $v$ prefer to imitate a strictly higher $\tilde{v}$, that is, if

$$
-\frac{G_{2}(\tilde{v}, v)}{G_{1}(\tilde{v}, v)}=-\frac{\left(F^{n-1}(\tilde{v})\right)^{\prime}}{G_{1}(\tilde{v}, v)}>0
$$

which is only satisfied if $G_{1}(\tilde{v}, v)<0$ for all $v$ at $\tilde{v}=v$.

By construction, $G(\tilde{v}, v)=0$ is satisfied at $\tilde{v}=v$, while $G_{2}(\tilde{v}, v)>0$ for all $\tilde{v}>v$, such that type- $v$ 's utility reaches a unique maximum at $\tilde{v}=v$.

Claim A6 (Strictly increasing $\beta$ ). $\beta$ is strictly increasing if $n \geq 4$ and $f^{\prime}(\cdot) \leq 0$ or if $n=3$ and $f^{\prime}(\cdot)<0$. 
Proof. Write

$$
\begin{aligned}
\beta^{\prime}(v)= & \frac{n-2}{n-1} \frac{1}{F(v)}\left(1-2 f(v) \frac{\int_{\underline{v}}^{v} F(x) d x}{F^{2}(v)}\right)+\frac{f(v)}{1-F(v)}\left(\frac{\int_{v}^{\bar{v}} x d F(x)}{1-F(v)}-v\right) \\
& -\frac{1}{(n-1)}\left(1+\frac{f^{\prime}(v) \int_{v}^{\bar{v}} f(x) d x}{(f(v))^{2}}\right),
\end{aligned}
$$

and apply partial integration on the second RHS term in (A8) to find

$$
\begin{aligned}
\beta^{\prime}(v)= & \frac{n-2}{n-1} \frac{1}{F(v)}\left(1-2 f(v) \frac{\int_{v}^{v} F(x) d x}{F^{2}(v)}\right)+\frac{f(v) \int_{v}^{\bar{v}}(1-F(x)) d x}{(1-F(v))^{2}} \\
& -\frac{1}{(n-1)}-\frac{1}{(n-1)} \frac{f^{\prime}(v) \int_{v}^{\bar{v}} f(x) d x}{(f(v))^{2}} .
\end{aligned}
$$

Note then that all RHS terms in (A9) are nonnegative if $f^{\prime}(\cdot) \leq 0$, except $-\frac{1}{(n-1)}$. If $f^{\prime}(\cdot)<0$ and $v>\underline{v}$, then $2 f(v) \frac{\int_{v}^{v} F(x) d x}{F^{2}(v)}<\frac{\int_{\underline{v}}^{v} d F^{2}(x)}{F^{2}(v)}=1$, such that $1-2 f(v) \frac{\int_{v}^{v} F(x) d x}{F^{2}(v)}>0$. On the other hand, the last term $-\frac{1}{(n-1)} \frac{f^{\prime}(v) \int_{v}^{\bar{v}} f(x) d x}{(f(v))^{2}}$ is strictly positive for $v<\bar{v}$. Both terms are zero for $f^{\prime}(\cdot)=0$. The main step is now to prove that $f^{\prime}(\cdot) \leq 0$ implies

$$
\frac{f(v) \int_{v}^{\bar{v}}(1-F(x)) d x}{(1-F(v))^{2}} \geq \frac{1}{2} .
$$

First note that $F$ is the uniform distribution, inequality (A10) is satisfied with equality. Note that $f^{\prime}(\cdot) \leq 0$ implies that $1-F(\cdot)$ is convex and write the inequality as

$$
2 \frac{\int_{v}^{\bar{v}}(1-F(x)) d x}{1-F(v)} \geq \frac{1-F(v)}{f(v)} .
$$

In the figure below, that the LHS of (A11), for $v=v^{\circ}$, is the gray area divided by the distance $1-F\left(v^{\circ}\right)$. Moreover, $\frac{\partial\left(1-F\left(v^{\circ}\right)\right)}{\partial v^{\circ}}=-f\left(v^{\circ}\right)$, such that this tangent line through $\left(v^{\circ}, 1-F\left(v^{\circ}\right)\right)$ crosses the $X$-axis at $v^{\circ}+\frac{1-F\left(v^{\circ}\right)}{f\left(v^{\circ}\right)}$. For $f^{\prime}(\cdot)=0$, it must be that $v^{\circ}+\frac{1-F\left(v^{\circ}\right)}{f\left(v^{\circ}\right)}=\bar{v}$, such that the inequality in (A11) is always satisfied with equality. If however $f^{\prime}(v)<0$ at some $v>v^{\circ}$, this strictly increases the LHS but not the RHS of (A11), such that the inequality is strictly satisfied.

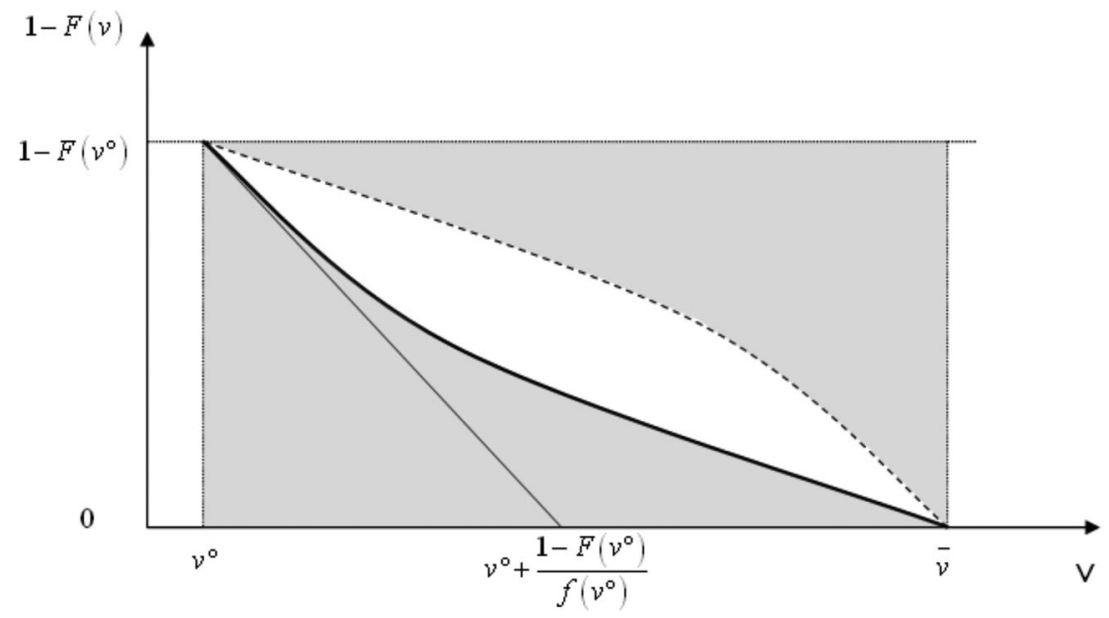


Thus, $f^{\prime}(\cdot) \leq 0$ implies that

$$
\frac{f(v) \int_{v}^{\bar{v}}(1-F(x)) d x}{(1-F(v))^{2}} \geq \frac{1}{2} \geq \frac{1}{(n-1)} .
$$

Hence, $\beta^{\prime}(\cdot)>0$ for $n>3$, while for $n=3$, we need $f^{\prime}(\cdot)<0$ to guarantee $\beta^{\prime}(\cdot)>0$.

\section{Proof of Lemma 2}

Claim A7 ( $\beta$ weakly increasing). If in a D1 PBE $v^{\prime}$ exits at $b^{\prime}$, then no $v^{\prime \prime}<v^{\prime}$ exits at $b^{\prime \prime}>b^{\prime}$.

Proof. Assume that $v^{\prime \prime}$ stays until $b^{\prime \prime}$. If type $v^{\prime}$ exits at $b^{\prime}$, then what she can win by staying is not better than what can be expected by exiting. The expected payoff of exiting at $b^{\prime}$ is identical for the $v^{\prime}$ and $v^{\prime \prime}$ types, while $v^{\prime}$ benefits strictly more from winning than $v^{\prime \prime}$, such that $v^{\prime \prime}$ should strictly prefer to exit at $b^{\prime}$.

Assume then a PBE with $v^{\prime}$ exiting at $b^{\prime}, v^{\prime \prime}<v^{\prime}$, and $b^{\prime \prime}>b^{\prime}$ an out-of-equilibrium exit strategy. Then if type- $v^{\prime \prime}$ equilibrium strategy is so low that $\mathcal{M}^{+}\left(b^{\prime \prime}, v^{\prime}\right) \subseteq \mathcal{M}^{+}\left(b^{\prime \prime}, v^{\prime \prime}\right) \cup \mathcal{M}^{0}\left(b^{\prime \prime}, v^{\prime \prime}\right)$, then type $v^{\prime \prime}$ would strictly prefer to exit at $b^{\prime}$ above her equilibrium strategy, a contradiction. Hence, $\mathcal{M}^{+}\left(b^{\prime \prime}, v^{\prime \prime}\right) \cup \mathcal{M}^{0}\left(b^{\prime \prime}, v^{\prime \prime}\right) \subset \mathcal{M}^{+}\left(b^{\prime \prime}, v^{\prime}\right)$, such that in any D1 PBE we have $\beta^{\prime}(\cdot) \geq 0$.

Claim A8 (No pooling). In any D1 PBE, no two types $v^{\prime} \neq v^{\prime \prime}$ exit at the same price $\tilde{b}$.

Let $\tilde{b}$ be the lowest price at which a nondegenerate set of types $\mathcal{O}=\{v \mid \beta(v)=\tilde{b}\}$ exit. By Claim A7, $\mathcal{O}$ is convex. For a nondegenerate set $\mathcal{O}$, a sufficiently small $\varepsilon>0$ can be found for which the winning equilibrium payoff at price $\tilde{b}+\varepsilon$ is strictly greater than at $\tilde{b}$. If $\tilde{b}+\varepsilon$ is out-of-equilibrium, then for $\varepsilon$ sufficiently small and $\mathcal{O}$ nondegenerate

$$
\sup (\mathcal{O})-\tilde{b}-\varepsilon+\frac{\int_{\sup (\mathcal{O})}^{\bar{v}} x d F(x)}{1-F(\sup (\mathcal{O}))}>\sup (\mathcal{O})-\tilde{b}+\frac{\int_{\inf (\mathcal{O})}^{\bar{v}} x d F(x)}{1-F(\inf (\mathcal{O}))}
$$

while the expected payoff of a loser exiting at $\tilde{b}+\varepsilon$ is at least as large as that of a loser exiting at $\tilde{b}$. If $\tilde{b}$ is chosen in PBE by higher types, this increases the RHS of inequality A12. Hence, $\beta^{\prime}(\cdot)>0$.

\section{Proof of Proposition 2}

Equation (5) is obtained by setting $\tilde{v}=v$ in (3) and solving for $\beta$. To see that $f^{\prime}(\cdot) \leq 0$ implies $\beta^{\prime}(\cdot)>0$, write

$$
\beta^{\prime}(v)=\frac{n-2}{n-1}\left[1-\frac{f(v)}{F(v)}\left(v-\frac{\int_{\underline{v}}^{v} x d F(x)}{F(v)}\right)\right]+\frac{f(v)}{1-F(v)}\left(\frac{\int_{v}^{\bar{v}} x d F(x)}{1-F(v)}-v\right) .
$$

The second RHS term is always strictly positive for $v \in[\underline{v}, \bar{v})$. To see that the first RHS term is always positive, note that the term between square brackets is strictly positive if

$$
F(v)>\left(v-\frac{\int_{v}^{v} x d F(x)}{F(v)}\right) F^{\prime}(v)
$$
which is always satisfied. Indeed for $f^{\prime}(\cdot) \leq 0, F$ is concave such that $F(v) \geq F^{\prime}(v)(v-\underline{v}) \geq\left(v-\frac{\int_{\underline{v}}^{v} x d F(x)}{F(v)}\right) F^{\prime}(v)$, with
the last inequality strict for $v \in(\underline{v}, \bar{v}]$. 
For $\beta$ as in (5), the exit rule in (3) fixes for every $v$ a unique $\tilde{v}$, as

$$
\frac{\partial}{\partial \tilde{v}}\left(-\beta(\tilde{v})+\frac{1}{1-F(\tilde{v})} \int_{\tilde{v}}^{\bar{v}} x d F(x)-\frac{\tilde{v}}{n-1}-\frac{n-2}{n-1} \frac{\int_{\underline{v}}^{\tilde{v}} x d F(x)}{F(\tilde{v})}\right)=-1 .
$$

Note also that no type $v$ wishes to mimic a different type $\tilde{v}$. By construction $\beta(\tilde{v})$ is such that (3) is satisfied with equality for $v=\tilde{v}$ and such that for $v>\tilde{v}$ the benefits of winning (LHS) are strictly greater than the RHS when mimicking $\tilde{v}$ 's strategy. The latter is the opposite if $v<\tilde{v}$.

\section{Proof of Proposition 3}

Let $\beta^{\mathrm{II}}$ and $\beta^{\mathrm{E}}$ denote the equilibrium biding function, respectively, of the second-price and the English auctions; $\mathrm{ER}^{\mathrm{II}}$ and $\mathrm{ER}^{\mathrm{E}}$ denote the expected revenue, respectively, of the second-price and the English auctions. As previously established, both bidding functions are identical up to the two following additional terms in the second-price auction:

$$
\beta^{\mathrm{II}}(v)-\beta^{\mathrm{E}}(v)=\frac{1-F(v)}{F(v)} \frac{n-2}{n-1}\left(v-\frac{\int_{\underline{v}}^{v} x d F(x)}{F(v)}\right)+\frac{(1-F(v))}{(n-1) f(v)}>0 .
$$

Expected revenues in both auctions are expectations of the bidding strategy at the equilibrium for the distribution of the second-highest type among $n$. It follows that $\mathrm{ER}^{\mathrm{II}}>\mathrm{ER}^{\mathrm{E}}$.

\section{Proof of Proposition 4}

We denote $V_{k}^{(n)}$ the $k$-highest-order statistic out $n$ draws. Remark that when the winner's identity and her bid are disclosed, the same information is revealed to the outside observer in the first-price auction and the second-price auction. Therefore these two auctions are revenue equivalent (see Proposition 2 of Giovannoni \& Makris, 2014). To compute the expected revenue $\mathrm{ER}^{\mathrm{B}}$ we can then use the first-price auction. The fully separating function at the equilibrium for the first-price when the winner's identity and her bid are revealed, denoted $\beta^{\mathrm{I}, \mathrm{B}}$, has been established by Giovannoni and Makris (2014) and is given by

$$
\beta^{\mathrm{I}, \mathrm{B}}(v)=\frac{2}{F^{n-1}(v)} \int_{\underline{v}}^{v} x d F^{n-1}(x)-\frac{1}{F^{n-1}(v)} \int_{\underline{v}}^{v} \frac{1}{F(y)} \int_{\underline{v}}^{y} x d F(x) d F^{n-1}(y)+\frac{1}{F^{n-1}(v)} \int_{\underline{v}}^{v} F^{n-1}(x) d x .
$$

Apply partial integration on the second and last RHS term in (A13) to obtain, respectively,

$$
\frac{1}{F^{n-1}(v)} \int_{\underline{v}}^{v} F^{n-1}(x) d x=v-\frac{1}{F^{n-1}(v)} \int_{\underline{v}}^{v} x d F^{n-1}(x)
$$

and

$$
\begin{aligned}
& \frac{1}{F^{n-1}(v)} \int_{\underline{v}}^{v} \frac{1}{F(y)} \int_{\underline{v}}^{y} x d F(x) d F^{n-1}(y) \\
= & \frac{n-1}{F^{n-1}(v)} \int_{\underline{v}}^{v} \int_{\underline{v}}^{y} x d F(x)\left(F^{n-3}(y)\right) d F(y) \\
= & \frac{n-1}{n-2} \frac{\int_{\underline{v}}^{v} x d F(x)}{F(v)}-\frac{1}{n-2} \frac{\int_{\underline{v}}^{v} x d F^{n-1}(x)}{F^{n-1}(x)},
\end{aligned}
$$


and substitute these in (A13) to obtain

$$
\beta^{\mathrm{I}, \mathrm{B}}(v)=v+\frac{n-1}{n-2}\left(\mathbb{E}\left(V_{1}^{(n-1)} \mid V \leq v\right)-\mathbb{E}(V \mid V \leq v)\right) \quad \text { with } \quad \lim _{v \rightarrow \underline{v}^{+}} \beta^{\mathrm{I}, \mathrm{B}}(v)=\underline{v} .
$$

We first write the expected revenue of the three auctions in a convenient form. When the winner's identity and her bid are revealed, the expected revenue of the second-price auction is

$$
\begin{aligned}
\mathrm{ER}^{\mathrm{B}} & =\int_{\underline{v}}^{\bar{v}} \beta^{\mathrm{I}, \mathrm{B}}(x) d F^{n}(x) \\
& =\mathbb{E}\left(V_{1}^{(n)}\right)+\frac{n-1}{n-2} \mathbb{E}\left(V_{2}^{(n)}\right)-\frac{n-1}{n-2} \int_{\underline{v}}^{\bar{v}} \frac{1}{F(y)} \int_{\underline{v}}^{\bar{v}} 1_{x \leq v} x d F(x)\left(F^{n}(y)\right)^{\prime} d y \\
& =\frac{n-1}{n-2} \mathbb{E}\left(V_{1}^{(n)}\right)+\frac{n-1}{n-2} \mathbb{E}\left(V_{2}^{(n)}\right)-\frac{n}{n-2} \mathbb{E}(V) .
\end{aligned}
$$

When the winner's identity and her payment are revealed, the expected revenue of the English auction is

$$
\begin{aligned}
\mathrm{ER}^{\mathrm{E}}= & (n-1) n \int_{\underline{v}}^{\bar{v}}\left(\frac{n-2}{n-1}\left(v-\frac{\int_{\underline{v}}^{v} x d F(x)}{F(v)}\right)+\frac{\int_{v}^{\bar{v}} x d F(x)}{1-F(v)}\right) F^{n-2}(v)(1-F(v)) f(v) d v \\
= & n(n-2) \int_{\underline{v}}^{\bar{v}} v F^{n-2}(v) f(v) d v-n(n-2) \int_{\underline{v}}^{\bar{v}} v F^{n-1}(v) f(v) d v \\
& -(n-2) n \int_{\underline{v}}^{\bar{v}} \frac{\int_{\underline{v}}^{v} x d F(x)}{F(v)} F^{n-2}(v)(1-F(v)) f(v) d v \\
& +(n-1) n \int_{\underline{v}}^{\bar{v}} \frac{\int_{v}^{\bar{v}} x d F(x)}{1-F(v)} F^{n-2}(v)(1-F(v)) f(v) d v \\
= & n \frac{n-2}{n-1} \mathbb{E}\left(V_{1}^{(n-1)}\right)-(n-2) \mathbb{E}\left(V_{1}^{(n)}\right)-(n-2) n \int_{\underline{v}}^{\bar{v}} \int_{\underline{v}}^{\bar{v}} 1_{x<v} x d F(x) F^{n-3}(v)(1-F(v)) f(v) d v \\
& +(n-1) n \int_{\underline{v}}^{\bar{v}} \int_{\underline{v}}^{\bar{v}} 1_{x>v} x d F(x) F^{n-2}(v) f(v) d v \\
= & n \frac{n-2}{n-1} \mathbb{E}\left(V_{1}^{(n-1)}\right)-(n-2) \mathbb{E}\left(V_{1}^{(n)}\right)-(n-2) n \int_{\underline{v}}^{\bar{v}} \int_{x}^{\bar{v}} F^{n-3}(v)(1-F(v)) f(v) d v x d F(x) \\
& +n \int_{\underline{v}}^{\bar{v}} \int_{\underline{v}}^{x} d F^{n-1}(v) x d F(x),
\end{aligned}
$$

such that

$$
\mathrm{ER}^{\mathrm{E}}=-\frac{n}{n-1} \mathbb{E}(V)+n \mathbb{E}\left(V_{1}^{(n-1)}\right)-\frac{n^{2}-3 n+1}{n-1} \mathbb{E}\left(V_{1}^{(n)}\right)
$$

When the winner's identity and her payment are revealed, the expected revenue of the second-price auction is

$$
\begin{aligned}
\mathrm{ER}^{\mathrm{II}}= & \int_{\underline{v}}^{\bar{v}} \beta^{\mathrm{II}}(x) d\left(n F^{n-1}(x)-(n-1) F^{n}(x)\right) \\
= & \frac{n}{n-1} \mathbb{E}\left(V_{2}^{(n-1)}\right)-\frac{n}{n-3} \mathbb{E}(V)+\frac{n}{n-3} \mathbb{E}\left(V_{1}^{(n-2)}\right)-\frac{n}{n-1} \mathbb{E}\left(V_{1}^{(n-1)}\right)+\mathbb{E}\left(V_{1}^{(n)}\right) \\
& +n \int_{\underline{v}}^{\bar{v}}(1-F(y))^{2} F^{n-2}(y) d y .
\end{aligned}
$$

Claim A9 (English auction with payment vs. second-price auction with winner's bid revealed). In the D1 $\mathrm{PBE} E R^{\mathrm{B}}>\mathrm{ER}^{\mathrm{E}}$. 
Proof. We use that

$$
\mathbb{E}\left(V_{2}^{(n)}\right)=n \mathbb{E}\left(V_{1}^{(n-1)}\right)-(n-1) \mathbb{E}\left(V_{1}^{(n)}\right)
$$

to write

$$
\mathrm{ER}^{\mathrm{E}}=-\frac{n}{n-1} \mathbb{E}(V)+\mathbb{E}\left(V_{2}^{(n)}\right)+\frac{n}{n-1} \mathbb{E}\left(V_{1}^{(n)}\right)
$$

such that

$$
\mathrm{ER}^{\mathrm{B}}-\mathrm{ER}^{\mathrm{E}}=\frac{1}{(n-1)(n-2)}\left(-n \mathbb{E}(V)+\mathbb{E}\left(V_{1}^{(n)}\right)+(n-1) \mathbb{E}\left(V_{2}^{(n)}\right)\right)>0 .
$$

Claim A10 (Second-price auction: winner's payment vs. winner's bid revealed). In the D1 PBE ER ${ }^{\mathrm{II}}>\mathrm{ER}^{\mathrm{B}}$.

Proof. We use (A15) to write

$$
\mathrm{ER}^{\mathrm{II}}=n \frac{n-2}{n-3} \mathbb{E}\left(V_{1}^{(n-2)}\right)-n \mathbb{E}\left(V_{1}^{(n-1)}\right)-\frac{n}{n-3} \mathbb{E}(V)+\mathbb{E}\left(V_{1}^{(n)}\right)+n \int_{\underline{v}}^{\bar{v}}\left((1-F(y))^{2} F^{n-2}(y)\right) d y
$$

Then

$$
\mathrm{ER}^{\mathrm{II}}-\mathrm{ER}^{\mathrm{B}}=n\left(\begin{array}{c}
\mathbb{E}\left(V_{1}^{(n)}\right)-\frac{(n-2)+(n-1)}{n-2} \mathbb{E}\left(V_{1}^{(n-1)}\right)+\frac{n-2}{n-3} \mathbb{E}\left(V_{1}^{(n-2)}\right) \\
-\frac{1}{(n-2)(n-3)} \mathbb{E}(V)+\int_{\underline{v}}^{\bar{v}}\left((1-F(y))^{2} F^{n-2}(y)\right) d y
\end{array}\right) .
$$

Note then that

$$
\begin{aligned}
\int_{\underline{\underline{v}}}^{\bar{v}}\left((1-F(y))^{2} F^{n-2}(y)\right) d y & =\int_{\underline{v}}^{\bar{v}} F^{n-2}(y) d y-2 \int_{\underline{v}}^{\bar{v}} F^{n-1}(y) d y+\int_{\underline{v}}^{\bar{v}} F^{n}(y) d y \\
& =2 \mathbb{E}\left(V_{1}^{(n-1)}\right)-\mathbb{E}\left(V_{1}^{(n)}\right)-\mathbb{E}\left(V_{1}^{(n-2)}\right),
\end{aligned}
$$

because by partial integration

$$
\bar{v}=\int_{\underline{v}}^{\bar{v}}\left(y F^{n-2}(y)\right)^{\prime} d y=\int_{\underline{v}}^{\bar{v}} F^{n-2}(y) d y+\int_{\underline{v}}^{\bar{v}} y d F^{n-2}(y)
$$

and the same for the other terms. Then

$$
\mathrm{ER}^{\mathrm{II}}-\mathrm{ER}^{\mathrm{B}}=n\left(-\frac{1}{n-2} \mathbb{E}\left(V_{1}^{(n-1)}\right)+\frac{1}{n-3} \mathbb{E}\left(V_{1}^{(n-2)}\right)-\frac{1}{(n-2)(n-3)} \mathbb{E}(V)\right)
$$

Then write

$$
\begin{aligned}
\mathrm{ER}^{\mathrm{II}}-\mathrm{ER}^{\mathrm{B}} & =n \int_{\underline{v}}^{\bar{v}} y\left(-\frac{n-1}{n-2} F^{n-2}(y)+\frac{n-2}{n-3} F^{n-3}(y)-\frac{1}{(n-2)(n-3)}\right) d F(y) \\
& =n \int_{0}^{1} y(u)\left(-\frac{n-1}{n-2} u^{n-2}+\frac{n-2}{n-3} u^{n-3}-\frac{1}{(n-2)(n-3)}\right) d u
\end{aligned}
$$


with $u \equiv F(y)$ and $y(u)=F^{-1}(u)$, and define

$$
G(u)=-\frac{n-1}{n-2} u^{n-2}+\frac{n-2}{n-3} u^{n-3}-\frac{1}{(n-2)(n-3)} .
$$

Note then that

$$
\int_{0}^{1} G(u) d u=-\frac{1}{n-2}+\frac{1}{n-3}-\frac{1}{(n-2)(n-3)}=0
$$

while $G(0)=-\frac{1}{(n-2)(n-3)}$ and $G(1)=0$. Moreover, given $G^{\prime}(u)=u^{n-4}(-(n-1) u+n-2), G$ is strictly increasing on $\left[0, \frac{n-2}{n-1}\right]$ and strictly decreasing on $\left[\frac{n-2}{n-1}, 1\right]$. Thus, there exists $0<u^{\star}<\frac{n-2}{n-1}$, such as $G(u)$ is strictly negative on an interval $\left[0, u^{\star}\right)$ and strictly positive on $\left(u^{\star}, 1\right)$, while $\int_{\left(u^{\star}, 1\right)} G(u) d u=-\int_{\left[0, u^{\star}\right)} G(u) d u>0$. Note then that $y(u)=F^{-1}(u)$ is a strictly increasing function. Then by the intermediate value theorem we can find two values $0<y_{1}<y_{2}$ such that

$$
\mathrm{ER}^{\mathrm{II}}-\mathrm{ER}^{\mathrm{B}}=y_{1} \int_{\left[0, u^{\star}\right)} G(u) d u+y_{2} \int_{\left(u^{\star}, 1\right)} G(u) d u
$$

while by the above

$$
\mathrm{ER}^{\mathrm{II}}-\mathrm{ER}^{\mathrm{B}}=\left(y_{2}-y_{1}\right) \int_{\left(u^{\star}, 1\right)} G(u) d u>0 .
$$

\section{Proof of Proposition 5}

Consider the equilibrium bidding strategy in the second-price auction given by (2), when the winner's identity and her payment are revealed. Then, using (A17) and similar computations from above, the expected revenue is

$$
\mathbb{E R}^{\mathrm{II}}=\mathbb{E}\left(V_{2}^{(n)}\right)+\int_{\underline{v}}^{\bar{v}} \mathbb{E}(V \mid V \geq y) d\left(n F^{n-1}(y)-(n-1) F^{n}(y)\right)-\mathbb{E}\left(V_{1}^{(n)}\right)+\frac{2 n}{n-1} \mathbb{E}\left(V_{1}^{(n-1)}\right)-n \mathbb{E}(V) .
$$

When only the winner's identity is revealed, the expected revenue is

$$
\mathbb{E R}^{\mathrm{Id}}=\mathbb{E}\left(V_{2}^{(n)}\right)+\int_{\underline{v}}^{\bar{v}} \mathbb{E}(V \mid V \geq y) d F^{n-1}(y)+\frac{1}{n} \mathbb{E}\left(V_{1}^{(n)}\right)-\mathbb{E}(V)
$$

Hence,

$$
\begin{aligned}
\mathrm{ER}^{\mathrm{Id}}-\mathrm{ER}^{\mathrm{II}}= & (n-1) \int_{\underline{v}}^{\bar{v}} \mathbb{E}(V \mid V \geq y) d\left(F^{n}(y)-F^{n-1}(y)\right)+\frac{n+1}{n} \mathbb{E}\left(V_{1}^{(n)}\right) \\
& -\frac{2 n}{n-1} \mathbb{E}\left(V_{1}^{(n-1)}\right)+(n-1) \mathbb{E}(V) .
\end{aligned}
$$

Remark that $\mathbb{E}(V \mid V \geq y)$ is strictly increasing and then $\int_{\underline{v}}^{\bar{v}} \mathbb{E}(V \mid V \geq y) d\left(F^{n}(y)-F^{n-1}(y)\right)>0$. Moreover,

$$
\begin{aligned}
\frac{n+1}{n} \mathbb{E}\left(V_{1}^{(n)}\right)-\frac{2 n}{n-1} \mathbb{E}\left(V_{1}^{(n-1)}\right)+(n-1) \mathbb{E}(V) & =\int_{\underline{v}}^{\bar{v}} y\left((n+1) F^{n-1}(y)-2 n F^{n-2}(y)+n-1\right) d y \\
& =\int_{0}^{1} y(u)\left((n+1) u^{n-1}-2 n u^{n-2}+n-1\right) d u
\end{aligned}
$$


with $u \equiv F(y)$ and $y(u)=F^{-1}(u)$. Let us define $G(u)=(n+1) u^{n-1}-2 n u^{n-2}+n-1$. Note then that $G(0)=n-1, G(1)=0$, and $G^{\prime}(v)=v^{n-3}\left(\left(n^{2}-1\right) v-2 n(n-2)\right)<0$ for $v \in[0,1]$ and $n \geq 4$. It follows that $G$ is a positive function for $v \in[0,1]$, hence the result.

\section{Proof of Proposition 6}

We established in Proposition 5 that $\mathrm{ER}^{\mathrm{Id}}>\mathrm{ER}^{\mathrm{II}}$ and Giovannoni and Makris (2014) determined in Part I of their Proposition 4 that $\mathrm{ER}^{\mathrm{A}} \geq \mathrm{ER}^{\mathrm{Id}}$ for $n$ sufficiently large if $f^{\prime}(\cdot) \leq 0$ (condition for the equilibrium existence when the winner's payment is revealed). Therefore, $\mathrm{ER}^{\mathrm{A}}>\mathrm{ER}^{\mathrm{II}}$ for $n$ sufficiently large.

Developing the computations of (A18), the expected revenue for the second-price auction, when the winner's identity and her payment are revealed, becomes

$$
\mathrm{ER}^{\mathrm{II}}=\mathbb{E}\left(V_{2}^{(n)}\right)+\frac{2 n}{n-1} \mathbb{E}\left(V_{1}^{(n-1)}\right)-n \mathbb{E}(V)
$$

When all bidders' identity and their bids are revealed, the expected revenue is

$$
\begin{aligned}
\mathrm{ER}^{\mathrm{A}} & =\mathbb{E}\left(V_{2}^{(n)}\right)+n \int_{\underline{v}}^{\bar{v}}(1-F(y)) d y \\
& =\mathbb{E}\left(V_{2}^{(n)}\right)+n(\mathbb{E}(V)-\underline{v}) .
\end{aligned}
$$

Therefore,

$$
\mathrm{ER}^{\mathrm{A}}-\mathrm{ER}^{\mathrm{II}}=2 n\left(\mathbb{E}(V)-\frac{1}{n-1} \mathbb{E}\left(V_{1}^{(n-1)}\right)-\frac{\underline{v}}{2}\right) .
$$

Remark that $(n-1) \mathbb{E}(V)>\mathbb{E}\left(V_{1}^{(n-1)}\right)$. Then, if $\underline{v}=0, \mathrm{ER}^{\mathrm{A}}-\mathrm{ER}^{\mathrm{II}}>0$. Using $\mathrm{ER}^{\mathrm{II}}-\mathrm{ER}^{\mathrm{E}}$ established in Proposition 3 , the result follows. 